IZA DP No. 9165

Children of Migrants:

The Impact of Parental Migration on Their Children's

Education and Health Outcomes

Xin Meng

Chikako Yamauchi

June 2015 


\title{
Children of Migrants: The Impact of Parental Migration on Their Children's Education and Health Outcomes
}

\author{
Xin Meng \\ Australian National University \\ and IZA \\ Chikako Yamauchi \\ National Graduate Institute for Policy Studies
}

\author{
Discussion Paper No. 9165 \\ June 2015
}

IZA
P.O. Box 7240
53072 Bonn
Germany

Phone: +49-228-3894-0

Fax: +49-228-3894-180

E-mail: iza@iza.org

\begin{abstract}
Any opinions expressed here are those of the author(s) and not those of IZA. Research published in this series may include views on policy, but the institute itself takes no institutional policy positions. The IZA research network is committed to the IZA Guiding Principles of Research Integrity.

The Institute for the Study of Labor (IZA) in Bonn is a local and virtual international research center and a place of communication between science, politics and business. IZA is an independent nonprofit organization supported by Deutsche Post Foundation. The center is associated with the University of Bonn and offers a stimulating research environment through its international network, workshops and conferences, data service, project support, research visits and doctoral program. IZA engages in (i) original and internationally competitive research in all fields of labor economics, (ii) development of policy concepts, and (iii) dissemination of research results and concepts to the interested public.
\end{abstract}

IZA Discussion Papers often represent preliminary work and are circulated to encourage discussion. Citation of such a paper should account for its provisional character. A revised version may be available directly from the author. 


\section{ABSTRACT \\ Children of Migrants: The Impact of Parental Migration on Their Children's Education and Health Outcomes}

In the past 15 years around 160 million Chinese rural workers migrated to cities to work. Because of restrictions on migrant access to local health and education system a large cohort of migrant children are left-behind in rural villages and growing up without parental care. This paper examines how parental migration affects children's health and education outcomes. Using the Rural-Urban Migration Survey in China (RUMiC) data we are able to measure the share of children's lifetime during which parents migrated away from home. By instrumenting this measure of parental migration with weather changes in their home village when they were young we find a sizable adverse impact of exposure to parental migration on children's health and education outcomes. We also find that what the literature has always done (using contemporaneous measure for parental migration) is likely to underestimate the effect of exposure to parental migration on children's outcomes.

JEL Classification: J38, 128

Keywords: migration, children, education, health, China

Corresponding author:

Xin Meng

Research School of Economics

College of Business and Economics

Australian National University

HW Arndt Building 25a

ACT 0200

Australia

E-mail: Xin.Meng@anu.edu.au 


\section{Introduction}

The human capital development of children has long been a great interest to economists. This is so not only because children's education and health outcomes today have a significant implication about their own social and economic wellbeing in the future, but also because children are the future of a society and how they are doing today as a group will predict the quality of human capital supply in the future for the society as a whole.

The unprecedented economic growth in China in the past few decades has led to a large scale rural-urban migration. In 2011, 160 million rural workers have migrated to cities to work (NBS 2012). This number is expected to grow rapidly in the coming years, with rural-urban migrant workers already accounting for more than 40 percent of the total urban labor force.

The large scale rural-urban migration may have significant impact on the human capital development of future generations. In particular, China's institutional restrictions on rural-urban migration prevent adult migrants from bringing their children with them when they choose to work in cities. The Household Registration System (hukou) limits rural migrant workers and their families' access to subsidized education, health care and other public services which are available to local residents in cities. As a result, rural parents often leave their children behind in rural villages when they migrate to cities. Children who remain in rural areas either live with other family members or enroll in boarding schools, without the care and supervision of their parents.

A significant number of children is being left-behind by their migrating parents in rural China. A study by the All-Women Federation China in 2006 estimates that 58 million children aged 0-18 are left-behind in rural villages due to parental migration (40 million 0-15 years of age), accounting for 28 per cent of all rural children. Also, the survey of 5000 migrant households, conducted by the Rural-Urban Migration in China (RUMiC) Project, suggests that around $57 \%$ of the migrant children aged 0-15 were left-behind in rural villages in 2008 .

Although parental migration often brings higher income and hence potentially more economic resources for children's education and health investment, lack of parental care can also have adverse effects on left-behind children. ${ }^{1}$ The net effect of parental migration depends on the relative magnitude of the two effects and it is largely an empirical issue. Several studies have found the positive income effect. For example, Yang (2008) finds

\footnotetext{
${ }^{1}$ There is a large body of literature on the determinants of children's development and learning processes, which clearly demonstrates the importance of parental care (see, for example Whitebook et al., 1989; Love et al., 1996; Lamb, 1998; McLanahan and Sandefur, 1994; Sigle-Rushton and McLanahan, 2002; Ginther and Pollak, 2003).
} 
that remittances from migrants increase educational expenditures and children's schooling in the Philippines. Similar positive impact on schooling is also found for El Salvador (Edwards and Ureta, 2003). For Mexico, girls from less educated families are found to obtain more years of schooling if one of their household member migrated to the U.S. (Hanson and Woodruff, 2003), or if their fathers migrated when they were very young (Antman, 2011). Other studies however have found the negative effect of parental migration. For instance, parental migration in China is followed by an increase in chores carried out by children aged around 7-12 (Chang et al., 2011; de Brauw and Mu, 2011). In Mexico, paternal migration is found to reduce children's study hours and increase work hours, particularly among boys aged 12-15 years. McKenzie and Rapoport (2011) also report that girls aged 16-18 in Mexico become more engaged in household chores if a member in the household is a migrant.

Despite the fact that a large number of left-behind children have been exposed to parental migration for a long time in China, many studies on the impact of parents' migration on left-behind children's human capital development focus on the immediate impact of parental absence. They are also based on small sample size and/or data from limited geographic regions. Partly reflecting geographic heterogeneity, their findings are mixed. For instance, Meyerhoefer and Chen (2011) uses the data for two northeastern provinces of Hebei and Liaoning and finds that parental migration is correlated with a delay in educational enrolment among girls aged 7-15. Zhang et al. (2014) uses the longitudinal data on test scores from a county in Hunan Province and shows that a significant negative effect arises only for children left behind by both of the parents. On the other hand, Chen et al. (2009) uses data from inland province of Shaanxi and finds that paternal out-migration is associated with an improvement in the children's test scores. Using the longitudinal data from the western province of Gansu, Lee and Park (2010) also finds positive impacts on the enrollment for boys and test scores for girls, but negative impacts on the psychological well-being of both gender. While the mixed finding may be attributed to differences in the identification strategies, it is also likely that small and unrepresentative data play a role. Notable exceptions in terms of geographic coverage include the studies based on the China Health and Nutrition Survey. De Brauw and Mu (2011) reports that children aged 7-12 are more likely to be underweight while younger children aged 2-6 are less likely to be overweight when a member of their household has migrated between the waves of 1997, 2000, 2004 and 2006. Using the same data for a different time period however, Chen (2013) does not find a significant impact on the body mass index for children aged 6-16.

It is unfortunate that, due to data limitation, these existing studies tend to focus on 
the short-run effects of parental migration, by either comparing before and after the start of parental migration or using the migration status in the previous year as the variable of interest. An more important issue, however, is how a cumulative parental migration affects children's health and education outcomes. That is, how an increase in the amount of time children spend in the absent of parental care affects their outcomes; or in other words, the "dose- or exposure-effect" of parental absence. Even if there are only small changes in children's outcomes associated with changes in parental migration status within a year, these effects can cumulate if parents are away from home for many years. Although the effect of parental migration in the previous year might partially reflect such a cumulative effect, it cannot fully capture the effect.

This paper contributes to the literature in the following ways. First, we use a large representative panel survey data of 8000 rural households, covering nine provinces from different regions in China. The data come from the Rural Household Survey of the RuralUrban Migration in China (RUMiC) Project.

Second, the RUMiC survey has detailed information on parental migration activities. As such, we are able to measure the cumulative duration of migration during which parents were absent from children's life. To the best of our knowledge, this is the only study which examines the cumulative effect of parental migration on children's health and education outcomes.

Third, we not only investigate the impact of parental migration on children's outcome but try to examine the channels through which such effect occurs. In particular, we examine the impact of parental migration on various investment into children's education.

Finally, we are aware of the issue of endogeneity in parental migration decision and try to mitigate the problem by adopting the Instrumental Variable (IV) approach. We use as instruments the weather shocks occurred when parents were young and before children were born, and the distance between one's home village and the provincial capital cities. The validity of the first IV lies on the fact that rural individuals are most likely to migrate for work when they are aged around late teens and early 20s, weather shocks, which can reduce agricultural income, are likely to induce rural youth to emigrate to cities. However, these shocks are unlikely to directly affect children who have not yet born. The second IV, distance to the provincial capital city, is valid because it captures both cost and the need to migrate and hence should be highly correlated with parental migration. At the same time as the household registration system (hukou) in China restricted people from re-allocating in the past 60 year $^{2}$ and hence where one's home village is is likely to be

\footnotetext{
${ }^{2}$ The rural-urban migration in China is under a "guest worker" system, whereby migrants are unable to settle in cities (see Meng, 2012).
} 
exogenously determined.

Our results suggest that children's lifetime exposure to parental migration significantly worsens health and education outcomes. We also find that left-behind children spent less time studying after schools and their families invest less on tutoring outside school environment relative to children whose parents were not migrated. It is also found that left-behind children are more likely to be enrolled in boarding schools, which has been found to provide low quality cares (REAP, 2009).

The remaining of the paper is structured as follows. The next section provides some institutional background which is important in understanding the issue. Section 3 discusses the data. Empirical methods are presented in Section 4, which is followed by the discussion of the results. Section 6 investigates the channels through which parental migration affects left-behind children's outcomes. Concluding remarks are given in Section 7.

\section{Background}

Ever since the Communist Party rose to power in 1949, China has had segregated rural and urban economies. Rural-urban migration was strictly restricted before the mid 1980s. As market oriented economic reform deepened, demand for unskilled labor in cities increased. To meet this demand, the government gradually relaxed the migration restrictions, but up until today migrants are still treated differentially from urban local people. In particular, migrant workers are restricted in the type of job they can obtain and in access to urban social welfare and social services, such as education, health care, unemployment benefits, and pensions (Meng and Manning, 2010). These restrictions prevent migrant workers from staying in cities for long and from bringing their families to cities. They often work in the cities for a few years, depending on their personal and family circumstances and then go back to their country home. Sometimes, they migrate back and forth.

As access to schools and health care in cities are very costly for migrants, many of them leave their children behind in rural villages. For example, the RUMiC 2008 survey of migrant household in cities show that among the 2300 children aged 0 to $15,57 \%$ were left-behind in rural areas. Out of these left-behind children, 30\% of them were looked after by one of the parents who stayed behind, and $59 \%$ of them were with grandparents or other relatives. The remaining $8 \%$ were at boarding schools.

Left-behind children may be disadvantaged with regard to their nutrition intake, health outcomes, and school performance if alternative caretakers of left-behind children have less time to spend with the children or pay less attention to their day-to-day needs. Alter- 
natively if left-behind children are taken care of in boarding schools, the living conditions and management system of boarding schools could be important. In rural China, anecdotal evidence suggests that "the quality of the facilities and the nature of the management (of the boarding schools) might best be described as horrific. The safety, hygiene, supervision, diet and nutrition are all serious problems to these boarding schools." (REAP, 2009). ${ }^{3}$ A resent study has reported that boarding school students in rural areas are 9 centimeters shorter than the relevant median height set by WHO (Shi and Zhang, 2010). Another study finds boarding schools have a negative impact on students' school performance as well (Mo, Yi, Zhang, Shi, Rozelle, and Medina, 2012).

\section{Data}

\subsection{Data sources}

The analysis is drawn from the data collected for the Rural-Urban Migration in China (RUMiC) Project, which is an annual longitudinal survey in China. The survey started in 2008, covering nine provinces or municipalities that are major sending or receiving areas of rural-to-urban migration. In each province, three separate random samples were drawn: rural households, urban local households, and a rural-to-urban migrant households. The sample size of the three samples is $8,000,5,000$, and 5,000, respectively. In this paper, we mainly utilize the sample of rural households from the second and third waves (2009 and $2010)^{4}$

The rural surveys were conducted by National Bureau of Statistics (NBS). The 8000 households (in 800 rural villages) in our survey provinces which are included in the regular NBS annual Rural Household Sruvey (RHS) are surveyed between March and June each year. All household members who are officially registered in the household are included in the survey. Members who are not officially registered in the household but have been living there for 6 months or more are also included in the survey. Information on household members who were not present at the time of the survey was reported by other household members.

The RUMiC survey has a very rich array of information. It includes basic information for adults (who are aged 16 years or above) such as education, employment, migration

\footnotetext{
${ }^{3}$ The situation may have improved in recent years after the significant investment into rural schools after 2009. The authors recently visited some rural schools in one county and found that most schools have had new buildings and the living conditions at these schools have improved significantly.

${ }^{4}$ The first wave is not used because, as discussed below, two of the key outcome variables were not available in the first wave data and one of the key questions on the duration of parental migration was only asked in the second wave.
} 
experience and anthropometry. The survey also asked parents or guardians to report their children's anthropometry (if aged 0-15 years) and school test scores (if aged 7-15 years). In addition, the survey conducted a uniformed mathematics test for most primary school children (grade one to six) in five out of the nine rural sample provinces in $2011 .^{5}$

\subsection{Outcome variables}

Our main outcome variables for children's health status are the z-scores for height-for-age and weight-for-age (see Appendix A for details on how these z-scores are generated). If parental migration has any impact on the child's health status, it is likely to be found in his/her height-for-age, which reflects the health and nutrition conditions in the long-run. While weight-for-age reflects both height-for-age and weight-for-height, if wasting is not prevalent, it is also likely to indicate the long-run health/nutritional conditions (de Onis and Blossner, 1997). We do not use weight-for-height or BMI as outcomes because they are more likely to reflect temporary changes in nutrition and health conditions.

The outcome variables we use for children's school achievement are the final exam scores attained in the last school term for the subjects of Chinese and mathematics. If parental absence leads to limited supervision and discipline of children, their study habits may not develop as well as they might develop under parental care, which can result in lower test scores.

These outcome variables were reported by parents or guardians, who are likely to have good knowledge of the children's anthropometry and test scores. For health outcomes, rural primary schools normally measure height and weight during its annual basic health check-up. Younger children who have not started schooling are also invited by village clinics to have similar annual regular check-up. Regarding the test scores, most schools in China have good communication channels with parents. In addition to the parental meetings regularly organised each semester, parents also receive reporting cards, in the form of a booklet, which records the child's assignments as well as final test scores (see, for example, Chen and Feng, 2007). Even if some parents are not fully aware of the children's outcomes, to the extent that these measurement errors occur randomly, it does not affect our estimates.

The test scores are likely to be comparable across children in the sample. The contents of exam papers are likely to be consistent across different regions because all the schools use one of the three textbook series, all of which closely follow the National Curriculum Standard - the standard for basic education (grade one through to grade nine) designed

\footnotetext{
${ }^{5}$ The test was not conducted in the remaining four rural sample provinces because of the cost and complexity of conducting the test in rural areas.
} 
by the Ministry of Education. This is particularly true for the core subjects of Chinese, Mathematics, and English. While the full test scores may vary across schools, we normalize test scores by dividing them by the full test score used in the child's school, which were also reported by parents/guardiants. To control any remaining differences that may exist, we include provincial dummy variables in the regression analysis. ${ }^{6}$

As a robustness check for both potential parental reporting errors and the inconsistency of exam papers across different regions, we also use the mathematics score obtained from the uniformed test we conducted in the $2011 .^{7}$

The analysis for children's height-for-age and weight-for-age Z-scores includes children ages $0-15$ years, and the analysis for the test scores is conducted using the sample of children aged 7-15 years. The outcome variables are likely to be comparable among these groups of children because the Z-scores take into account differential growth patterns for each group defined by age and gender, and the test scores are in terms of percentage. We also control a set of age- and gender-specific dummy variables in the regression.

Instead of raw values of these outcomes, we use the average value over the 2009 and 2010 waves because the original data contain missing values and a large variance. ${ }^{8}$ The use of the average value reduces the cases with missing values or reporting errors.

\subsection{Key treatment variables}

As discussed earlier, we focus mainly on the cumulative exposure effect of parental migration on children. A frequently used indicator for parental migration is based on very recent migration experience, such as the number of months during which parents or household members were away from home in the previous year or whether parents were away in the past few years. However, the parental inputs provided before the previous year (or the time of the survey) are also likely to be important in shaping current health status and educational achievement of the children. In order to measure the children's exposure to parental migration more comprehensively, we define the share of a child's lifetime in

\footnotetext{
${ }^{6}$ Provincial governments have the flexibility to choose from three different textbook series. Usually the same textbook series is used within a province or prefecture.

${ }^{7}$ The test instruments were designed specifically for RUMiC project by the Research Institute for Education Statistics and Measurement (RIESM) at Beijing Normal University. The RIESM organized teachers from the nine sample provinces (including the sample province without rural areas) in order to design and test the instruments. They created two types of instruments: one for Year 1-3 and the other for Year 4-6. These instruments are designed to take about 30 minutes. University students were sent to the sample households to conduct the test during the months of July through August.

${ }^{8}$ For the small number of cases with obvious reporting errors, we replaced the original data with the likely values. For instance, we use the adjusted score of 0.7 when the original own score is 700 while the full score is 100; we use the average between 120 and 125 when the original height was reported to be $120 \mathrm{~cm}$ in $2008,600 \mathrm{~cm}$ in 2009 , and $125 \mathrm{~cm}$ in 2010 .
} 
which his/her parents were away from rural home, hereafter refers to as 'lifetime exposure to parental migration', as:

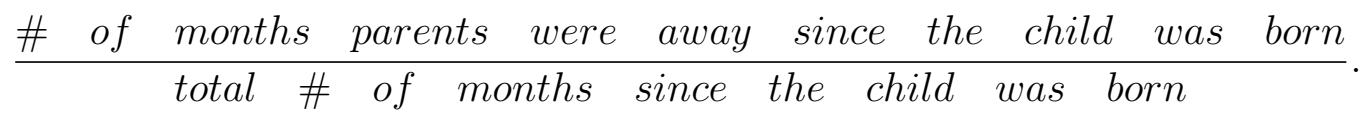

If a parent has never migrated, this share takes the value of zero. If a parent has been away all the time since a child was born, this share takes the value of one. If a parent started working away from home some time after a child was born, this share takes a value somewhere between zero and one. We use the following two pieces of information regarding when parents started migration to construct the numerator of our lifetimeexposure measure. The first is the start year of the first migration spell. This is available for parents who have ever migrated for work. The second is the month and year in which the 2008 migration spell started, which was asked for parents who were away from home for three months or more in $2008 .^{9}$

More specifically, RUMiC survey 2008, 2009, and 2010 waves report detailed information of the number of months parents were away in the previous year (2007, 2008, and 2009). Thus, if the start year of the first spell of parental migration (or the start year of the 2008 migration spell) was before the birth year of the child, we assume that parents were away in all the months since the birth of the child till the end of 2006 . We count the number of months in that period, and this duration is added to the number of months the parents were away from home between 2007 and 2009. If the the start year of the first migration spell (or the start of the 2008 migration spell) was after the child's birth year, we count how many months had past since the start of parental migration till the end of 2006. Then, we add that to the duration of migration between 2007 and 2009 . We calculate these two types of numerators for each parent (see Appendix A for more details). The numerator is then divided by the child's age measured in months.

The two numerators generated from either initial migration or the start of the 2008 spell may both suffer from measurement error problemes. First, the duration calculated based on the first migration spell is likely to overestimate the true duration of parental migration, because we assume that parents were away in all the months between their first migration and the end of 2006. However, churning back amd forth between city jobs and villages among migrants in China is very common. Our calculation counts periods which migrants return to home villages as part of their migration period. ${ }^{10}$ Second, the

\footnotetext{
${ }^{9}$ All the adults were asked whether they were away in the previous year, and if so, when the episode of migration started. This question was not asked in the 2008 and 2010 waves.

${ }^{10}$ For example, one third of the people who have ever migrated and reported the initial year of migration
} 
duration of parental migration calculated based on the start of the 2008 migration spell is likely to underestimate the true duration of parental migration because parents may have had other spells prior to the 2008 spell. ${ }^{11}$ In order to purge a possible bias which might stem from these measurement errors, we use the instrumental variable method (see estimation strategy section for detailed discussion).

To compare our results with the existing literature, we also estimate the effect of contemporaneous parental migration using the following two measures: (1) the share of the average number of months the mother and/or father was away from home in 2008 and 2009 (divided by 12), and (2) a dummy variable indicating whether mother or father was away in either 2008 or 2009.

\subsection{Sample}

There are 5,043, 4,762 and 4,326 children aged 0-15 years in 2008, 2009 and 2010 waves, respectively.

Our education outcome variables are only available in 2009 and 2010 waves. To maximize the working sample size and also minimize the measurement errors, we take averages of the outcome, the treatment and the control variables between 2009 and 2010 waves. Our measure for parental migration requires the information on the duration of migration reported in each wave of the RUMiC data. In order to calculate parental migration history up to 2009, our analytical sample is based on the group of children who were surveyed in both 2008 and 2009 waves. If the child also have 2010 information, he/she need to be surveyed in all three waves. There are 4,548 children aged 0-14 years in the 2008 wave of the RUMiC survey. ${ }^{12}$ These are the children who can potentially be included in either the 2009 and/or 2010 waves because they would still be classified as children aged under 16 years in the 2009 or 2010 waves. $^{13}$ In addition we exclude 359 children

in the three waves of the RUMiC data spent the entire previous year in rural homes. This indicates that parents with migration experience might have had years without migration between the initial year and 2006.

${ }^{11}$ For those who migrated in 2008 , the average duration between the year in which the 2008 episode started and 2008 is 2.4 years, whereas the duration between the start year of the first migration spell and 2008 averages to 7.1 years. This huge difference indicates that, on average, these parents had more than one episode of migration, with their first migration spell starting in 2000 , and the current spell starting in 2005 .

${ }^{12}$ Among the original sample of children aged 0-14 years, $142(3.1 \%)$ attrit in the second wave, and additional $845(19 \%)$ attrit in the third wave. There was a changing survey team within NBS between 2009 and 2010. As a result around 11 villages which were in the 2009 wave were not included in the 2010 wave, another 8 villages included in the 2010 wave were not included in the 2009 wave. In total there are 19 villages not matched between the two waves.

${ }^{13}$ The RUMiC asked child-specific questions for children aged 0-15 years. Thus, once they turn 16 years of age, they are classified as adults under the RUMiC framework, and the test scores and other 
who spend sometime in 2007, 2008 or 2009 outside their rural homes in order to focus on children who are left-behind in rural areas. Excluding all the missing values, our final analytical samples for health and education outcomes are 2,988 and 2,233, respectively. ${ }^{14}$ These samples will also be used for our contemporaneous effect analysis.

To assess whether our final sample is random, we compare those who are included in the final sample with those who were excluded. Table 1 presents the results. Column 1 shows the results of regressing the dummy variables indicating whether the child is included in the analytical health sample or not on a vector of child, parental and household characteristics controlling for provincial fixed effects. Column 2 presents the results for the education sample. These results suggest that in both samples, there is no statistically significant differences in the outcome variable between children who are included and those who are excluded from our final sample. However, we observe some statistically significant differences for children and parental characteristics, as well as for village level information. For example, children included in the health sample are older and have slightly lower birth weight (35 grams), whereas those included in the education sample are 3.6 percentage point more likely to be girls. In addition, fathers of children who are included in our health sample are one year older and have 0.16 fewer years of education than fathers of children who are not included in the sample. For the education sample, however, we do not observe any statistically significant difference in parental characteristics. With regard to village characteristics, there are slight differences in distance to the nearest junior high school and bus station, but the differences are very small.

\subsection{Summary Statistics}

Table 2 presents the summary statistics of the outcome, treatment, and other explanatory variables for the health and education samples. Panel A of the table presents children's outcome and treatment variables, while Panel B shows summary statistics for children, parents, and households' characteristics.

The average height and weight z-scores are -1.49 and 0.16 , respectively. Note that zscores compare each child's height and weight with the U.S. age specific height and weight distribution. Thus, the average of -1.49 of height z-score indicates that on average our sample children are 1.49 standard deviation below the U.S. age-standardized height distribution, whereas the 0.16 weight z-score indicates that they are 0.16 standard deviation

school-related information are no longer collected for them. The RUMiC also contains the child-specific questions for children older than 15 but still in school, regardless of where they live. However, this paper focuses on children aged 0-15 years residing in the rural households.

${ }^{14}$ The sample for education measures excludes children who were not at school (aged 0-6). 
above the age-standardized weight distribution for the U.S. children. Panel A of Figure 1 presents the distributions of these z-scores. It shows that the height z-score distribution is skewed to the left, while the weight z-score almost follows a normal distribution. Both weight and height z-scores are trimmed as they contain extreme values (see Data Appendix for details). For the school aged children (the education sample) the Chinese and maths test scores are averaged around 82 and 84 percent, respectively. Panel B of Figure 1 shows that there are more children with above 90 mathematics test scores than those for the Chinese test score.

The treatment indicators are reported for fathers and mothers, separately. The indicator for children's lifetime exposure using the start of the 2008 migration spell as the measure suggests that, for our health sample, on average, the father was away from home for 17 percent of children's life time, and the mother was away for 11 percent of their life time. The alternative indicators for children's lifetime exposure using the start of the initial migration spell exhibit higher values: for an average child, the father (mother) was away from home for 49 (34) percent of the child's life time. This is not surprising because the alternative indicators are more likely to overestimate the true duration of parental migration since the birth of the child.

Figure 2 presents the distribution of children's lifetime exposure based on the 2008 parental migration episode. It shows that around half of the children whose fathers were away for some period of their life, whereas around $31 \%$ of the children whose mothers were away for some period of their lives (Panel A of Figure 2). Among those children whose father and/or mother was away for at least a month since they were born, 3 to 4 percent of father/mother were away for the entire of the children's life (Panel B of Figure 2). The average duration of the father's absence from home amounts to 32 percent of the child's life time if we exclude children whose father was never away. The equivalent figure for the mother is 30 percent. These statistics indicate that both fathers and mothers spend about the same length of time away from their children once they leave home, although mothers are less likely to do so.

For the contemporaneous migration measure we find that in the previous year, fathers (mothers) on average were away for 3.5 (2.3) months for the health sample, while for the education sample the average months father and mother being away was slightly shorter. This may reflect that parents are less likely to migrate when their children are at school. Among the health sample, $44 \%$ children has their fathers being away in the previous year and 30\% mothers were away. For the education sample, again, both ratios are lower: $40 \%$ and $25 \%$, respectively.

Panel B of Table 2 presents children, parents, and household characteristics. Children 
in the health and education samples are, on average, 9.5 and 11.5 years old, respectively. Around $55 \%$ of them are males and their average birth weight is $3.2 \mathrm{~kg}$ for both sample. Their fathers and mothers are on average around $168 \mathrm{~cm}$ and $160 \mathrm{~cm}$ in height with around 8 and 7 years of schooling, ${ }^{15}$ respectively. The average age of fathers is 37 and 39 years of age for the health and education samples, respectively. On average, mothers are 2 years younger than fathers in both samples. Finally, the households in our samples, on average, have around 5 people. Approximately one third of the household members are children between age 0 and 15 .

\section{Estimation Strategy}

In this paper we examine the effect of parental migration on health and education outcomes of children who are left-behind in rural hometown. Consider the following equation:

$$
Y_{i j t}=\beta_{1} M_{i j t-1}+\beta_{2} X_{i j t}+\nu_{i j t},
$$

where $Y_{i j t}$ is the health or education outcome for child $i$, in village $j$, at time $t$ (the average of the outcome variables over the year 2009 and 2010). $M_{i j t-1}$ measures either the contemporaneous parental migration in time $t-1$, or the child $i^{\prime} s$ lifetime exposure to parental migration at time $t-1 . X_{i j t}$ is a vector of child-, parent-, and village-level characteristics which may affect children's outcomes. These variables include child's birth weight, a set of gender specific age dummy variables for children, parental age, education and height, and a set of four village-level characteristics which measures village public facility accessibility (the distance from the village to the nearest primary school, junior high school, health clinic and the bus station). We also control for the provincial fixed effects. $\nu_{i j t}$ is the error term. ${ }^{16}$

It is important to remember that our conceptual framework indicates that parental migration may affect children's outcomes in two directions: It reduces direct care from parents on children's health and education, which in turn, could have adverse effect on these outcomes. At the same time, parental migration could increase households income and hence may potentially have a positive effect on children's health and education outcomes. Thus, the estimated effect of parental migration, $\beta_{2}$ in Equation (1), is a net of

\footnotetext{
${ }^{15}$ Note that around $1 \%$ and $5 \%$ of fathers and mothers, respectively, have missing values for the years of schooling variable. We included them as zero years of schooling and using a dummy variable to identify this group.

${ }^{16}$ The error term, $v_{i j t}$, is assumed to be independent across households in the basic OLS estimation. In the IV estimation, we assume that it is independent across groups defined by county and cohort. As discussed below, our IVs vary across counties and cohorts.
} 
the two effects. The reason we do not directly control for the household per capita income or parental remittances variables is mainly due to the potential endogeneity problem they may introduce.

Equation (1) is first estimated using OLS regressions. However, the estimated results are by no means causal effects. This is because parental migration is an endogenous variable. First, parental migration decisions may be affected by children's health and education outcomes. Parents of children who are healthy and doing well at school may be more likely to choose to migrate or stay away for longer time. If this is the case, the OLS estimates will be underestimates of the true effects of migration. Second, it is also possible that healthier and more able parents are more likely to choose to migrate. These unobserved characteristics can be inherited by their children, and hence, are positively related to children's health and education outcomes. If so, this will also cause underestimation of the actual effect of parental migration on children's outcomes. Third, our major independent variable, $M_{i j t-1}$, may suffer from measurement error problem (see discussions in Section 3), which can also bias our estimated results if Equation (1) is estimated using OLS. Note that the contemporaneous parental migration measure is less likely to suffer from the measurement problem than that of the accumulated parental migration measure.

Considering these problems, the ideal way to investigate the causal relationship is probably to adopt the Instrumental Variable (IV) approach. We use two potential instruments for children's lifetime exposure to parent migration and the contemporaneous parental migration measures.

The first instrument is the number of weather shocks occurred when a parent (for father and mother separately) was aged 16-25, which is the time when individuals are most likely to initiate migration (Meng, 2012). For each parent, we specify the years in which she or he was aged 16-25 years. In those ten years, we count how many times extraordinarily little rain or high temperature happened in spring. ${ }^{17}$ If parents experienced too little rain or too high temperature in spring, that can reduce agricultural outputs of the year. If this happened many times during youth, parents might have decided to migrate to cope with the income losses. On the other hand, these weather shocks occurred before children were born. Our oldest sample children were 15 years of age in 2009, or born in 1994. On average, their fathers were aged 27 at their births.

More specifically, we measure rainfall or temperature shocks based on the 30-year (between 1980 and 2010) overall annual spring months averages. If, in a particular year a weather station observed 1.5 standard deviation below the 30 year rainfall average or 1.5

\footnotetext{
${ }^{17}$ We focuse on the spring months because March through May (or in Chinese Calendar term, Chun Fen to Xiao Man) is the period which is believed to be crucial to the harvest of the year.
} 
standard deviation above the 30 year temperature average we define them as rainfall or temperature shocks. We count the number of these two types of shocks in the ten-year during which the parent were aged 16-25, then the interaction term is created between the number of years with very high temperature and the number of years with little rain in spring. While we tested for many other specifications for weather shocks, this interaction term is most correlated with children's lifetime exposure to parental migration.

The ten-year youth interval is unlikely to be sensible for older parents who turned 25 years of age before 1980, because the migration to cities was not a realistic option before 1980. Thus, for these cohorts, we assign the equivalent interaction term for years between 1980 and 1989.

The weather data are from the China's National Meteorological Information Centre (NMIC). The historical daily rainfall and temperature information is available for 824 weather stations across China between 1980 and 2010. Out of these 824 stations, 75 have been assigned to our 82 sample counties as the nearest weather stations. ${ }^{18}$

The second instrument is the distance between home village and the capital city of the province where the child lives. This instrument captures the combination of potential migration cost (the further away the village is from the provincial capital city, the higher the cost) and the need to migrate (the closer the village is to the capital city the less need to migrate to city to get a job). The validity of this instrument depends on the fact that over the past 60 years it has always been extremely difficult for rural people to change their hukou registration status from rural to urban or even from one rural village to another. Normally individuals who are born in a rural village are registered with a rural hukou at their birth village for the rest of their life. There are very few exceptions. This feature of China's Household Registration System implies that in general where individuals live is exogenous. This basic exogeneity in household registration location insures that how far away one's home village is from the capital city of one's home province, whether one's own village is rich or poor, whether one's own village suffered from natural disasters or not are exogenous, out of individuals' control. We derive this instrument from the Google Earth, where we measured the straight line distance between our 82 survey counties and their respective provincial capital cities. We add this distant measure to the measure we obtained from the 2008 RUMiC Rural Village Survey which inquires the distance between the village and the county city.

However, there may remain concerns over the two instruments. The weather shocks are measured at the time when parents were aged 16 to 25. During that period some

\footnotetext{
${ }^{18}$ To allocate the nearest weather station for our sample counties, we marked all the counties and the stations in Google Earth based on their latitude and longitude and then measured their straight line distance.
} 
children might have born and hence their health and education outcomes may be affected by these weather events. In the sensitivity test section, we will test the robustness of using weather event occured when parents were aged 16 to 21 as the Chinese legal marriage age for men and women are 23 and 21 years, respectively, and out of wedlock birth is extremly rare in rural China. The distance variable may also suffer from the concern that the closer to the provincial capital city the better the economic conditions of the village. To mitigate this possibility, we include in our regression a vector of village public facility accessibility indicators, plus the average per capita income for the village, in addition to the provincial fixed effects.

\section{The Empirical Results}

Before discussing empirical results an important technical issue needs to be mentioned. Ideally, one would like to include both father's and mother's migration duration separately as measures of $M_{i j t-1}$ in the estimation of equation (1). However, these two variables are highly correlated. The correlation coefficient between the share of father's and mother's migration durations in child's life time for our sample is 78 percent. This level of correlation may be tolerable in the case of OLS estimation but not in the case of the IV (or 2SLS) estimation, where the correlation coefficient between the predicted lifetime exposure for father's and mother's migrations is 96 percent. Such a high level of multicollinearity results in insignificant estimates for either treatmental variables. Due to this problem, we estimate Equation (1) for mother's and father's impact separately.

\subsection{The OLS results}

The OLS results from the regressions of the relationship between children's lifetime exposure as well as contemporaneous parental migration variables and outcome variables are presented in Table 3. The results for the lifetime exposure regression indicate that, fathers' and mothers' accumulated migration years as proportion of children's life time are negatively but statistically significantly associated with children's height-for-age (Columns 1 to 2). For weight-for-age Z-scores the negative effect from exposure to mothers' migration becomes statistically significant. With regard to the education outcomes, however, we find small but statistically significant positive correlation between children's lifetime exposure to mothers' migration and children's education outcomes except for fathers' migration and children's Chinese test score, which is positive but statistically insignificant. These positive relationship can also be revealed from the unconditional relationship plotted in 
Figure 3, where we observe strong positive relationship between outcome variables, except height, and the parental migration ratio, especially for mothers.

Is this counterintuitive? Not necessarily. As discussed earlier, in the presence of reverse causality, omitted variable, and measurement errors, the unconditional relationship and the OLS estimations are more likely to be under-estimations of the actual causal effect children's lifetime exposure to parental migration on children's health and education outcomes. Intuitively it is easy to understand that parents make decisions to migrate. When their children are doing well, they may choose to leave, whereas when their children are not doing well they will choose to stay. At the same time, we understand that parents who choose to migrate may be a special group. They may be more risk loving, more competitive and more driven. These characteristics could be inherited by their children. As our regressions fail to control for these characteristics, the correlation observed from the regression may simply be a reflection of the artefact that driven parents have driven children.

In addition, the fact that our measure for long-run parental migration is very likely to suffer from measurement error problem also tend to generate under-estimated coefficients. There may be some evidence of this. As we know that the measures of the contemporaneous parental migration is less likely to suffer from large measurement errors than the long-run parental migration measures. The fact that we find statistically significantly negative correlation between the proportion of last year parents migrated away from home and children's health outcome variables whereas no relationship is observed when using children's lifetime exposure to parental migration as the treatment may suggest that the measurement errors play a role even though the magnitudes of the coefficients from the two parental migration measures are not directly comparable. Panel C of Table 3 further strengthen this argument: the treatment variable used in this panel is a dummy variable indicating if the father or mother ever migrated during the 2008 and 2009 period. Relative to the 'number of months migration' measure, this measure is even less likely to be measured with error. Here we observe that not only the health outcomes but also education outcome variables for fathers' migration indicator become statistically significantly negative.

With regard to other independent variables, we find that controlling for children's age, gender and birth weight, parental height is closely related to children's health outcome variables, while parental years of schooling is closely related to children's education outcome variables. Household size has some negative association with both children's health and education outcomes. 


\subsection{The IV Results}

We now discuss the IV results, which provide indications on how parental accumulated migration during the children's life time or their contemporaneous migration have affected children's health and education outcomes.

Table 4 reports the selected results from the first stage estimations. The results indicate that all instruments are highly significantly related to the variables of children's life-time exposure to parental migration (Panel A) or parental contemporaneous migration (Panel B). The instruments are stronger for parental contemporaneous migration measures than for the parental long-run migration measures. This is understandable as the latter involves not only whether parents migrated or not, but also the duration of parental migration and the age of the children at which parents started the 2008 spell of migration.

We observe that the more the severe drought occurred over the 10 years window when parents were age 16 to 25, the more likely the parents stayed longer away from the children. Also the farther away the parents went, the longer they stayed away from the children.

As discussed before, the distance between own village and provincial capital city is used to capture the combination of potential migration cost and the need to migrate to get a job in the city (the closer the village is to the capital city the less need to migrate). The sign for the relationship between the distance and migration measure is, therefore, ambiguous a priori. If distance captures the cost of migration, it should be negatively correlated with parental migration. But even here, because our migration measure has a duration component in it (accumulated parental migration during children's lifetime or number of months parents migrated last year), it could be argued that when the cost of migrating away is higher, the probability of stay away longer should also be higher. In addition, the closer one's own village is from the provincial capital cities, the less need for parents to live away from their children to be able to get a job in cities. In other words, they could travel daily to go to work. We observe a positive relationship between the distance and our endogenous variables. Thus, the IV is likely to capture the absence of nearby job opportunities and the costs of returning home.

Other coviarates in the first stage regression, which are statistically significant, include the child's birth weight, father's education level and age, household composition, as well as some of the village level economic conditions. All of the statistically significant covariates seem to have expected signs. The heavier the children at birth, the longer the parent migrated away from them. This seems to suggest reverse causality. Further, educated and younger fathers seem to have longer duration being away from their children. Parents from large families are more likely to move away for longer. Finally, parents from villages which have lower income are more likely to be away for longer period. 
The first three panel of Table 5 reports the IV results of children's long-term exposure to parental migration, while the last two panels report the IV results of contemporaneous parental migration effect.

Panel A of Table 5 reports the results from the full sample. We find that long-term exposure to parental migration is negatively and most of the time statistically significantly related to children's health and education outcomes.

The estimated long-term exposure effects suggest that every 10 percentage point increase in mother's migration duration reduces the child's height z-score by 0.34 , which is 19 percent of a standard deviation for the height-for-age z-score distribution for our sample (see Table 2 for the measure of standard deviations). For this sample, the average children's lifetime exposure to mother's migration is $9.5 \%$. Thus, for this sample, on average, long-term exposure will reduce children's height z-score by around $0.32(=0.34 \times 0.95)$. This effect is the average over all children whether the mother was away or not.

If we confine the calculation to those whose mother were actually migrated, the effect is larger. Among our sample, $32 \%$ of the children experienced mother migration and for them the average share of their lifetime with mother being absent is $30 \%$. Thus, for this group of children the long-term exposure to mother's migration is a $1.02(=0.34 \times 3)$ reduction in height-for-age $\mathrm{z}$-score, which is $60 \%$ of the standard deviation for the sample.

The effect of father's migration duration, as share of the child's lifetime, on children's height-for-age z-score is also negative but much smaller and statistically insignificant. Exposure to both parents' migration, however, has negative and statistically significant impact on weight-for-age z-score. Although weight-for-age-z score on itself may be not very meaningful, taking it together with the negative impact on height-for-age z-score may suggest that long-term exposure to parental migration can cause underweight in left-behind children.

We now turn to the education outcomes of children (Columns 5 to 8 of Table 5 ). With this sample, every 10 percentage point increase in long-term exposure to father's migration reduces the Chinese and mathematics test scores by 2.8 and 1.7 percentage points (25 and 15 percent of a standard deviation of the Chinese and mathematics test scores for the sample), respectively. On average for the whole sample of children, regardless whether the father has ever been away or not, fathers were away $11 \%$ of the children's lifetime, hence on average the fathers' migration effect on this sample is 3.1 and 1.9 percentage point reduction of Chinese and mathematics test scores, respectively. For the 44 percent of children whose fathers ever migrated - they were away $24 \%$ of the child's lifetime - the reduction on their Chinese and mathematics test scores caused by their fathers' migration is a 6.7 and 4.2 percentage points, respectively, and this accounts for 61 and 38 percent of 
the standard deviation of the Chinese and mathematics scores for the sample, respectively, which are very large effects.

For children whose mother have been away, the negative effect is larger for Chinese test score. A 10 percentage point increase in a child's long-term exposure to mother's migration reduces the child's Chinese test score by 3.6 percentage points. For this sample, the mothers have been away for an average of $6.3 \%$ of the children's lifetime and the effect for this sample as a whole is 2.3 percentage points reduction in Chinese test scores. There are $30 \%$ of children whose mothers have been away sometime in their lives, and the duration of mother's migration as percentage of the child's lifetime averages to $23 \%$. Thus, the treatment for this group is a reduction of 8.3 percentage points in Chinese scores, which accounts for 73.5 percent of the standard deviation of the Chinese scores for the sample. This is an even larger effect than the effects generated from the exposure to father's migration.

Panels $\mathrm{B}$ and $\mathrm{C}$ of Table 5 present the results by gender. In general, the negative significant effect persist in most cases for sons while the effects for daughters, although negative, are often not precisely estimated due, probably, to the instruments being too weak.

When we examine the contemporaneous effect of parental migration (Panels $\mathrm{E}$ and $\mathrm{F}$ of Table 5) we find that children with parents who migrated away in the previous year in general have negative outcomes both in terms of health and education. The IV estimates indicate larger negative effects, confirming the upward bias in the OLS estimates. Understandably, the size of the coefficients is smaller for the contemporaneous effect than those using the long-run exposure measure as the long-term exposure encompasses the contemporaneous effect. The literature often uses contemporaneous measure to capture parental migration effect. Our finding indicates that this is likely to underestimate the true effect of parental migration on children's outcomes.

\subsubsection{Robustness tests}

In this subsection we conduct three different sensitivity tests.

The first test is associated with how the 'long-run' parental migration is measured. Up until now, we have used the measure for parental migration calculated based on the start of the 2008 migration spell. As discussed earlier, this measure may under-estimate the actuall duration of parental migration since the child was born due to the possibility of multiple spells. The other measure we could use is to calculate the duration based on the start of the first migration spell. The migration indicator based on this spell is likely to overestimate the duration of parental migration, and thus, the estimated coefficient 
is likely to provide the lower bound for the effect of parental migration. We present the estimated results using this lower-bound measure of parental migration in Panel A of Table 6. The results are consistent with those observed using the 2008 spell (Panel A of the table) but the magnitude of the coefficients are indeed smaller.

The second set of tests is related to the concern that the extrem spring drought is measured for the time when parents were between age 16 and 25. Duing this time if the child was born, this could have direct effect on children's outcomes as well. To test this directly we redefine the drought variable to restrict it to the period when parents were between age 16 and 21. The 1980 Chinese Marriage Law stipulate that the marriage age for females and males are no earlier than 20 and 22, respectively. This age restriction has not changed since then. Restricting the measure for drought to when parents aged 16 to 21 will minimize the potential direct effect on children's outcomes. These results are reported in Panel B of Table 6. The results show that a such change in the definition of the IV does not affect the sign and the size of the coefficients much, especially for the education outcomes. Most coefficients are still statistically significant. However, the impact on height for both mother and father are not precisely estimated now.

Finally, we test the comparability of our education outcome variable. As discussed earlier even though we normalise the test scores obtained from the survey, the content of exam papers may be different across regions. To test whether our results obtained above on education is sensitive to the way our education outcome is measured we use data collected from a uniformed mathematical test conducted in 2011 for RUMiC sample households. We re-estimate the IV regression reported in Table 5 for a sub-group of children with consistent math-test results. The mathematical test was conducted only in five out of nine RUMiC rural sampling provinces and it was only for primary school children (years one to six). Thus, the number of observation for this test is much smaller. The detailed information on test instruments is presented in footnote 8 .

The selected results using the consistent mathematics test score as dependent variable are reported in Panel $\mathrm{C}$ of Table 6 . Due to the small sample size, the strength of the IVs has reduced dramatically. Nevertheless, the estimated coefficients from these equations all have the right sign and statistically significant at the $5 \%$ level.

The above sensitivity tests seem, to some extent, confirm that there is a strong negative impact of parental migration on left-behind children's education outcomes. The effect on health outcomes is found to be relatively weak and not stable. 


\section{How Parental Migration Affect Test Scores}

Why is it that parental migration has negative effect on children's school outcomes? In this section we look into whether and to what extent parental migration affect the level of inputs into children's schooling. In particular, we examine school starting age, distance to school, whether or not the child attends a boarding school, the number of hours the child studies after school, and various annual fees paid to school as well as private tutoring. We also include a variable which measures the difference between the child's current age and current grade. The normal gap should be 6 or 7 depending on when the child went to school. If the gap is larger, then it may suggest schooling repetition.

The model specification for these input equations is exactly the same as that specified in Equation (1). The IV results are reported in Table 7. We find that left-behind children are going to school earlier, but have larger gap between age and grade, they are more likely to be in boarding schools, they spend less time studying after-school and their family are paying less private tutoring fees.

A priori, it is not clear whether an early school starting age is good or bad for children's education. However, combining it with the fact that left-behind children are older for their grades even though they started school at younger age suggests that there might be considerable grade repetitions. This finding is consistent with Meyerhoefer and Chen (2011), who also find that left-behind children are more likely to repeat school grade.

The magnitude of the effects for the above statistically significant findings are rather large. Every 10 percentage points increase in long-term exposure to father and mother migration increases the child's age-grade gap by 0.28 and 0.41 of a year; increases the child's probability of going to boarding school by 8.6 and 7.1 percent; reduces the number of hours children study after-school by 2.1 and 2.7 hours per week, respectively. Note that on average our sample children spend 7 hours weekly studying after school. These are 30 to 42 percent reduction. Parental migration also reduces the private tutoring fee paid by 58 and 55 yuan, respectively. Perhaps the negative impact of parental migration on these inputs into children's schooling outcomes are all part of the reason why parental migration durations as share of children's lifetime have negative impact on left-behind children's education outcomes.

\section{Conclusion}

Using the RUMiC data, this paper has examined the impact of long-run exposure to parental migration on children's health and education outcomes. Unlike most studies in 
this area, we are able to measure the share of children's lifetime during which their parents were away from home. To the best of our knowledge, this is the first study providing the evidence on the effect of lifetime exposure to parental migration.

The unconditional relationships between our treatment (parental migration) and children's outcomes have revealed that there may exist a high degree of reverse causality problem. To mitigate this problem and problems of omitted variable and measurement errors, we adopted the instrumental variable approach. We instrumented the exposure to parental migration using the weather shocks which happened during parental youth and prior to child birth, as well as the distance to the provincial capital city.

One of our major findings is that both father and mother being away at some stage of children's life adversely affect children's school achievement measured by both Chinese and mathematics test scores. Exposure to mother's migration also negatively affects children's height-for-age and weight-for-age, whereas the effect of exposure to father's migration is negative but often not precisely estimated.

The size of the impact are quite large. For example, if a child's father was away for one quarter of the child's life, the child' Chinese and mathematic test scores are likely to be 7 and 4.3 percentage points lower, respectively, than a child whose father was never away. The same effect for exposure to mothers being away is a reduction of 9 percentage points for Chinese test scores.

Note that our estimated impact is a combination of the negative parental absent effect and a positive income effect generated from parental migration. Had we been able to control for the income effect the estimated parental absent effect could be even larger.

The other finding of importance is that when parents migrate and leave their children behind in the rural villages, children are more likely to go to boarding schools, and they spend considerably less time studing after school. Interestingly although parental migration increases household income, spending on children's private tutoring fees is lower for children whose parents migrate. All these negative effect on inputs into children's schooling should contribute to the negative impact on their school outcomes.

Finally, when comparing our results for children's lifetime exposure with contemporaneous effects we find that what the literature has always done (using contemporaneous measure) is likely to reflect the lower bound of the exposure effect.

China's rural-urban migration has affected tens of millions of rural children. More than 60 percent of migrant children are left-behind in rural villages, primarily because migrant children are have limited access in cities to public services such as education and health care. The large negative impact of parental migration on left-behind children's health and education outcomes uncovered by this study is alarming. If allowed to continue, the 
negative intergenerational impact of parental migration on future adults will affect the quality of future labour supply, reinforcing the lack of skills and widen income inequality. 


\section{References}

[1] All-China Women's Federation (2006), 'Quanguo nongcun liushou ertong gongzuo dianshi dianhua huiyi zaijing zhaokai' [National video conference on rural left-behind children], available at http://www.women.org.cn/manguage/big1.jsp?id=33853

[2] Antman, F., 2011, "The Impact of Migration on Family Left Behind", working paper, University of Colorado at Boulder.

[3] Black, D., Smith, J. and Daniel, K., 2005, "College quality and wages in the United States", German Economic Review, 6(3), pp. 415-443.

[4] Chang, Hongqin, Xiao-yuan Dong and Finona Macphail, 2011, "Labor Migration and Time Use Patterns of the Left-behind Children and Elderly in Rural China," World Development, 39(12), 2199-2210.

[5] Chen, Joyce J., 2013, "Identifying non-cooperative behavior among spouses: Child outcomes in migrant-sending households ", Journal of Development Economics, 100, $1-18$

[6] Chen, Xinxin, Qiuqiong Huang, Scott Rozelle, and Linxiu Zhang, "Migration, money and mother: The effect of migration on children's educational performance in rural China", Paper presented at the American Agricultural Economics Association Annual Meeting, Portland, OR, July 29-August 1, 2007.

[7] de Brauw, A., Mu, R., 2011, "Migration and the Overweight and Underweight Status of Children in Rural China", Food Policy 36(1), pp. 88-100.

[8] de Onis, Mercedes and Monika Blossner, 1997, WHO Global Database on Child Growth and Malnutrition, World Health Organization.

[9] de Onis, Mercedes, Adelheid W. Onyango, Elaine Borghi, Amani Siyam, Chizuru Nishidaa and Jonathan Siekmanna, 2007, Development of a WHO growth reference for school-aged children and adolescents, Bulletin of the World Health Organization 2007;85:660“C667.

[10] Du, Y., Gregory, R.G., and Meng, X., 2006, "Impact of the guest worker system on poverty and wellbeing of migrant workers in urban China" in Ross Gaunaut and Ligang Song (eds.) The Turning Point in China's economic Development, Canberra: Asia Pacific Press. 
[11] Edwards, A., Ureta, M., 2003, "International Migration, Remittances and Schooling: Evidence from El Salvador", Journal of Development Economics 72, pp. 429-461.

[12] Feng, Shuaizhang and Yuanyuan Chen, "School type and education of migrant children: Evidence from Shanghai", (in Chinese), forthcoming, Economics Quarterly.

[13] Ginther, D., and R. Pollak, 2003, "Does Family Structure Affect Children's Educational Outcomes?" NBER Working Paper 9628.

[14] Han, Jialing. 2003. Report on Migrant Children's Education in Beijing. In Peasant Migrants: Socioeconomic analysis of Peasant Workers in the Cities, edited by P. Li. Beijing: Social Science Publishing House.

[15] Hanson, G., Woodruff, C., 2003, "Emigration and Education Attainment in Mexico", working paper, University of California.

[16] Kuczmarski RJ, Ogden CL, Guo SS, et al., 2002, " 2000 CDC growth charts for the United States: Methods and development" National Center for Health Statistics, Vital Health Stat 11(246).

[17] Lamb, M. 1998. Non-parental childcare: context, quality, correlates and consequences. In Child Psychology in Practice, edited by I. Sigel and K. Renninger. New York: Wiley.

[18] Liang, Z., and Y.P. Chen. 2007. "The Educational Consequences of Migration for Children in China," Social Science Research, forthcoming.

[19] Lee, L., Park A., 2010, "Parental Migration and Child Development in China", Working Paper, Oxford University.

[20] Love, J. , P. Schochet, and A. Meckstroh. 1996, "Are they in danger? What research does-and doesn't-Tell us about childcare quality and children well-being". Mathematica Research Inc. [cited from http://www.mathematica-mpr.com].

[21] McKenzie, D., Rapoport, H., 2011, "Can Migration Reduce Educational Attainment? Evidence from Mexico", Journal of Population Economics, 24(4), pp. 1331-1358.

[22] McLanahan, S., and G. Sandefur. 1994. Growing Up with a Single Parent: What Helps, What Hurts. Cambridge: Harvard University Press.

[23] Meng, X. "Regional wage gap, information flow, and rural-urban migration," in Yaohui Zhao and Loraine West (eds) Rural Labor Flows in China, Berkeley: University of California Press, 251-277. 
[24] Meng, X., 2012, "Labor market outcomes and reforms in China", Journal of Economic Perspectives, 26(4), pp.75-102.

[25] Meng, X. and Zhang, J. "The Two Tier Labor Market in Urban China: Occupational and Wage Differentials Between Residents and Rural Migrants in Shanghai," Journal of Comparative Economics, 2001, 29(3), 485-504.

[26] Meng, X. and Manning, C., 2010, "The great migration in china and indonesiatrend and institutions" in X. Meng and C. Manning, with S. Li, and T.Effendi (eds) The Great Migration: Rural-Urban Migration in China and Indonesia, Edward Elgar Publishing Ltd.

[27] Meyerhoefer, c., Chen, C., 2011, "The Effect of Parental Labour Migration on Children's Educational Progress in Rural China", Review of Economics of the Household, 9(3), pp. 379-396.

[28] Mo, D, Yi, H. M., Zhang, L.X., Shi Y.J., Rozelle, S., and Medina, A., 2010, "Transfer paths and academic performance: The primary school merger program in China", REAP Working Paper 216.

[29] National Bureau of Statistics of China (NBS), 2012, China Statistical Yearbook, China Statistics Press, Beijin

[30] REAP, 2009, Boarding Schools, http://reap.stanford.edu/docs/boarding_schools/

[31] Rivkin, S. G., Hanushek, E. A., and Kain, J. F., 2005, "Teachers, Schools, and Academic Achievement", Econometrica, 73(2), pp.417-458.

[32] Rozelle, S., Ma, X.C., Zhang, L.X., and Liu, C.F., 2009, "Educating Beijing's migrants: A profile of the weakest link in China's education system", REAP Working Paper 212.

[33] Shi, Yaojiang and Linxiu Zhang, "Boarding school management (and PTAs) in China's poor rural areas",

[34] Sigle-Rusthon, W., and S. McLanahan. 2002. "Father Absence and Child Well-Being: A Critical Review," Center for Research on Well-Being Working Paper \#02-20.

[35] Yang, D., 2008, "International Migration, Remittances and Household Investment: Evidence from Philippine Migrants' Exchange Rate Shocks", The Economic Journal, 118(528), pp. 591-630. 
[36] Ye, Jingzhong, James Murray, and Wang Yi Huan, eds. 2005. Left-behind children in rural China: Impact study of rural labor migration on left-behind children in MidWest China. Beijing: Socail Sciences Academic Press.

[37] Whitebook, M, C. Howes, and D. Phillips. 1989. "Who cares? Child care teachers and the quality of care in America: Final report National Child Care Staffing Study." Oakland, CA: Child Care Employee Project.

[38] World Health Organization, 2006, WHO Child Growth Standards: Length/heightfor-age, weight-for-age, weight-for-length, weight-for-height and body mass indexfor-age: Methods and development, WHO.

[39] Zhang, Hongliang, Jere R. Behrman, C. Simon Fan, Xiangdong Wei, and Junsen Zhanga, 2014, "Does parental absence reduce cognitive achievements? Evidence from rural China," Journal of Development Economics, 111, 181-195.

[40] Zhao, Zhong, "Migration, Labor Market Flexibility, and Wage Determination in China: A Review," The Developing Economies, Jul. 2005, 43(2), 285-312. 
Table 1: Test for sample attrition bias

\begin{tabular}{|c|c|c|c|c|}
\hline \multirow{3}{*}{ Dependent variable } & \multicolumn{4}{|c|}{ Sample=children aged $0-13$ in the 1 st wave } \\
\hline & \multicolumn{2}{|c|}{$\begin{array}{l}1 \text { if included in the health sample } \\
\text { (1) }\end{array}$} & \multicolumn{2}{|c|}{$\begin{array}{l}1 \text { if included in the education } \\
\text { sample } \\
(2)\end{array}$} \\
\hline & $\begin{array}{l}\text { Coef } \\
\text { [S.E.] }\end{array}$ & $\mathrm{N}$ & $\begin{array}{l}\text { Coef } \\
\text { [S.E.] }\end{array}$ & $\mathrm{N}$ \\
\hline Height-for-age Z-score (2008) & $\begin{array}{l}-0.111 \\
{[0.086]}\end{array}$ & 3,146 & & \\
\hline Weight-for-age Z-score (2008) & $\begin{array}{c}-0.091 \\
{[0.058]}\end{array}$ & 3,660 & & \\
\hline Chinese test score (2009) & & & $\begin{array}{l}-0.002 \\
{[0.007]}\end{array}$ & 2,355 \\
\hline Math test score (2009) & & & $\begin{array}{l}-0.013 \\
{[0.008]}\end{array}$ & 2,348 \\
\hline Age (2010) & $\begin{array}{c}0.759 * * * \\
{[0.141]}\end{array}$ & 3,947 & $\begin{array}{c}-0.086 \\
{[0.112]}\end{array}$ & 2,847 \\
\hline Male dummy variable & $\begin{array}{l}-0.016 \\
{[0.018]}\end{array}$ & 3,947 & $\begin{array}{l}-0.036^{*} \\
{[0.022]}\end{array}$ & 2,847 \\
\hline Birth weight (g) & $\begin{array}{c}-34.911^{* *} \\
{[14.214]}\end{array}$ & 3,947 & $\begin{array}{l}-16.768 \\
{[16.858]}\end{array}$ & 2,847 \\
\hline Father's age (2010) & $\begin{array}{c}1.006 * * * \\
{[0.246]}\end{array}$ & 3,825 & $\begin{array}{c}0.299 \\
{[0.270]}\end{array}$ & 2,754 \\
\hline Father's years of education & $\begin{array}{c}-0.163 * * \\
{[0.073]}\end{array}$ & 3,770 & $\begin{array}{c}-0.069 \\
{[0.090]}\end{array}$ & 2,709 \\
\hline Father's height & $\begin{array}{c}0.026 \\
{[0.176]}\end{array}$ & 3,825 & $\begin{array}{c}0.122 \\
{[0.215]}\end{array}$ & 2,754 \\
\hline Number of household members (2008) & $\begin{array}{c}0.040 \\
{[0.047]}\end{array}$ & 3,947 & $\begin{array}{c}0.138 * * \\
{[0.054]}\end{array}$ & 2,847 \\
\hline Household per capita income (2008) & $\begin{array}{c}-33.264 \\
{[262.825]}\end{array}$ & 3,838 & $\begin{array}{c}283.317 \\
{[350.360]}\end{array}$ & 2,779 \\
\hline Distance to nearest primary school (2008) & $\begin{array}{l}-0.011 \\
{[0.019]}\end{array}$ & 3,947 & $\begin{array}{l}-0.030 \\
{[0.022]}\end{array}$ & 2,847 \\
\hline Distance to nearest junior high school (2008) & $\begin{array}{c}-0.088^{* * *} \\
{[0.031]}\end{array}$ & 3,947 & $\begin{array}{l}-0.033 \\
{[0.037]}\end{array}$ & 2,847 \\
\hline Distance to nearest bus stop (2008) & $\begin{array}{c}-0.109 * * * \\
{[0.040]}\end{array}$ & 3,947 & $\begin{array}{l}-0.088^{*} \\
{[0.049]}\end{array}$ & 2,847 \\
\hline Distance to nearest clinic (2008) & $\begin{array}{c}-0.033 \\
{[0.025]}\end{array}$ & 3,947 & $\begin{array}{c}0.009 \\
{[0.031]}\end{array}$ & 2,847 \\
\hline
\end{tabular}

Standard errors in brackets, ${ }^{* * *} \mathrm{p}<0.01,{ }^{* *} \mathrm{p}<0.05,{ }^{*} \mathrm{p}<0.1$

Note: Each regression controls for provincial fixed effects. 
Table 2: Summary Statistics

\begin{tabular}{|c|c|c|c|c|}
\hline \multirow[b]{2}{*}{ Outcome variables: } & \multicolumn{4}{|c|}{ "Panel A: Outcome and Treatment Variables } \\
\hline & \multicolumn{2}{|c|}{ Health Sample } & \multicolumn{2}{|c|}{ Education Sample } \\
\hline \multirow[t]{2}{*}{ Height-for-age Z-Score } & \multicolumn{2}{|c|}{-1.488} & & \\
\hline & \multicolumn{2}{|c|}{ [1.694] } & & \\
\hline \multirow[t]{2}{*}{ Weight-for-age Z-Score } & \multicolumn{2}{|c|}{0.161} & & \\
\hline & \multicolumn{2}{|c|}{$[1.272]$} & & \\
\hline & \multicolumn{2}{|c|}{0.817} \\
\hline \multicolumn{3}{|l|}{ Chinese test score (as \% of the full mark) } & \multicolumn{2}{|c|}{$[0.110]$} \\
\hline \multirow[t]{2}{*}{ Mathmatics test score (as \% of the full mark) } & & & & \\
\hline & & & & \\
\hline Treatment variables: & Father & Mother & Father & Mother \\
\hline Lifetime exposure to parent migration (2008 spell) & 0.155 & 0.095 & 0.108 & 0.063 \\
\hline & {$[0.263]$} & {$[0.213]$} & {$[0.214]$} & [0.169] \\
\hline$\%$ of Children with exposure $>0$ (2008 spell) & 0.477 & 0.315 & 0.443 & 0.279 \\
\hline Lifetime exposure to parent migration if exposure $>0$ & 0.324 & 0.301 & 0.243 & 0.225 \\
\hline & [0.301] & {$[0.287]$} & {$[0.266]$} & [0.256] \\
\hline Lifetime exposure to parent migration (initial spell) & 0.408 & 0.231 & 0.387 & 0.206 \\
\hline & [0.384] & [0.338] & [0.383] & [0.325] \\
\hline$\%$ of Children with exposure $>0$ (initial spell) & 0.641 & 0.430 & 0.617 & 0.398 \\
\hline Mean average no. of month last year parent mig & 3.377 & 2.095 & 2.997 & 1.767 \\
\hline & [4.418] & [3.784] & [4.259] & [3.564] \\
\hline$\%$ of children with last year parental migration $>0$ & 0.427 & 0.270 & 0.387 & 0.231 \\
\hline Observations & & & & \\
\hline & Panel B: & arent $\mathrm{Hoc}$ & and Villag & teristics \\
\hline Children's information: & $\mathrm{He}$ & & Educ & mple \\
\hline Age & & & & \\
\hline & & & & \\
\hline 1 if male & & & & \\
\hline birth weight (g) & & & & \\
\hline & & & & \\
\hline Household information: & & & & \\
\hline Household member & & & & \\
\hline & & & & \\
\hline$\%$ of hh members being female aged $>16$ & & & & \\
\hline$\%$ of hh members being male aged $>16$ & & & & \\
\hline$\%$ of hh members aged between 12 and 15 & & & & \\
\hline$\%$ of hh members aged between 0 and 11 (omitted) & & & & \\
\hline Parental information: & Father & Mother & Father & Mother \\
\hline Parent's height (2009/2010 average) & 168.44 & 160.32 & 168.37 & 160.29 \\
\hline & [4.989] & [4.893] & [5.118] & [4.882] \\
\hline Parent's years of schooling (2009/2010 average) & 8.20 & 7.19 & 8.06 & 6.99 \\
\hline & {$[2.142]$} & {$[2.674]$} & [2.145] & [2.751] \\
\hline Parent's age (2009/2010 average) & 37.92 & 36.35 & 39.56 & 37.96 \\
\hline & {$[6.556]$} & [6.334] & [5.995] & [5.601] \\
\hline$\%$ with missing parental years of schooling & 0.013 & 0.051 & 0.013 & 0.059 \\
\hline Village information: & & & & \\
\hline Distance to the nearest primary school & 1.269 & & 1.263 & \\
\hline & {$[0.532]$} & & [0.511] & \\
\hline Distance to the nearest junior high school & 2.007 & & 2.006 & \\
\hline & {$[0.852]$} & & [0.845] & \\
\hline Distance to the nearest bus stop & 2.158 & & 2.142 & \\
\hline & [1.172] & & [1.175] & \\
\hline Distance to the nearest clinic & 1.416 & & 1.432 & \\
\hline & {$[0.697]$} & & {$[0.718]$} & \\
\hline Average household income per capita (yuan) & $6,237.00$ & & $6,328.00$ & \\
\hline & {$[4,246]$} & & {$[4,689]$} & \\
\hline & & anel C: Ins & tal Variabl & \\
\hline Instruments: & Father & Mother & Father & Mother \\
\hline Number of hot years $*$ Number of years with little rain & 0.231 & 0.346 & 0.098 & 0.218 \\
\hline when parents were aged $16-21$ & {$[0.965]$} & {$[1.200]$} & [0.669] & [1.016] \\
\hline Distance from local village to provincial capital (1000km?) & 0.27 & & 0.273 & \\
\hline & [0.131] & & [0.130] & \\
\hline Observations & & & & \\
\hline
\end{tabular}


Table 3: OLS Results for Relationship between Children's Outcomes and Lifetime and Contemporaneous Exposure to Parental Migration

\begin{tabular}{|c|c|c|c|c|c|c|c|c|}
\hline & \multicolumn{8}{|c|}{ Panel A: Lifetime exposure to parental migration } \\
\hline & \multicolumn{2}{|c|}{ Height } & \multicolumn{2}{|c|}{ Weight } & \multicolumn{2}{|c|}{ Chinese } & \multicolumn{2}{|c|}{ Math } \\
\hline & $\begin{array}{c}\text { Father } \\
\text { [1] }\end{array}$ & $\begin{array}{c}\text { Mother } \\
\text { [2] }\end{array}$ & $\begin{array}{c}\text { Father } \\
\text { [3] }\end{array}$ & $\begin{array}{c}\text { Mother } \\
{[4]}\end{array}$ & $\begin{array}{c}\text { Father } \\
\text { [5] }\end{array}$ & $\begin{array}{c}\text { Mother } \\
{[6]}\end{array}$ & $\begin{array}{c}\text { Father } \\
\text { [7] }\end{array}$ & $\begin{array}{c}\text { Mother } \\
\text { [8] }\end{array}$ \\
\hline & [0.155] & [0.190] & [0.101] & [0.124] & [0.011] & [0.016] & [0.012] & [0.017] \\
\hline Child's birth weight & $0.015^{*}$ & $0.014^{*}$ & 0.005 & 0.005 & 0.000 & 0.000 & 0.000 & 0.000 \\
\hline & {$[0.007]$} & [0.007] & {$[0.005]$} & {$[0.005]$} & {$[0.000]$} & {$[0.000]$} & [0.001] & {$[0.001]$} \\
\hline \multirow[t]{2}{*}{ Mother's height } & $0.015^{* *}$ & $0.015^{* *}$ & $0.014 * * *$ & $0.013^{* * *}$ & 0.000 & 0.000 & 0.000 & 0.000 \\
\hline & {$[0.007]$} & [0.007] & {$[0.005]$} & {$[0.005]$} & {$[0.001]$} & {$[0.001]$} & {$[0.001]$} & {$[0.001]$} \\
\hline \multirow[t]{2}{*}{ Father's years of schooling } & -0.023 & -0.024 & $-0.038 * * *$ & $-0.038 * * *$ & $0.006 * * *$ & $0.006 * * *$ & $0.003 * *$ & $0.003^{* *}$ \\
\hline & [0.018] & [0.018] & {$[0.011]$} & {$[0.011]$} & {$[0.001]$} & {$[0.001]$} & {$[0.001]$} & {$[0.001]$} \\
\hline \multirow[t]{2}{*}{ Mother's age } & $0.025 * *$ & $0.025 * *$ & $0.021 * * *$ & $0.020 * * *$ & 0.002 & 0.002 & 0.001 & 0.001 \\
\hline & {$[0.012]$} & {$[0.012]$} & {$[0.008]$} & {$[0.008]$} & {$[0.001]$} & {$[0.001]$} & {$[0.001]$} & [0.001] \\
\hline \multirow[t]{2}{*}{ Number of household members } & $-0.095 * * *$ & $-0.098 * * *$ & $-0.034^{*}$ & $-0.030 *$ & $-0.003^{*}$ & $-0.004^{*}$ & -0.002 & -0.002 \\
\hline & {$[0.032]$} & [0.032] & [0.018] & {$[0.018]$} & {$[0.002]$} & {$[0.002]$} & {$[0.002]$} & [0.002] \\
\hline \multirow[t]{2}{*}{ Share of adults female member (aged $>=16$ ) } & $0.883^{* *}$ & $0.882 * *$ & $0.702 * * *$ & $0.730 * * *$ & $0.078 * * *$ & $0.076 * * *$ & $0.076 * * *$ & $0.074 * *$ \\
\hline & [0.394] & {$[0.396]$} & [0.242] & [0.242] & {$[0.028]$} & {$[0.028]$} & {$[0.029]$} & {$[0.029]$} \\
\hline \multirow[t]{2}{*}{ Share of adults male member (aged $>=16$ ) } & -0.110 & -0.132 & 0.011 & 0.064 & 0.007 & 0.005 & 0.045 & 0.041 \\
\hline & [0.435] & [0.438] & [0.268] & [0.267] & [0.029] & [0.029] & {$[0.030]$} & {$[0.030]$} \\
\hline \multirow[t]{2}{*}{ Shear of children aged 12 to 15} & 0.386 & 0.375 & 0.296 & 0.298 & 0.014 & 0.014 & 0.008 & 0.009 \\
\hline & [0.364] & [0.363] & [0.225] & {$[0.225]$} & {$[0.024]$} & {$[0.024]$} & {$[0.025]$} & {$[0.025]$} \\
\hline No. of months last year parents away/12 & [0.099] & {$[0.120]$} & {$[0.066]$} & {$[0.076]$} & {$[0.007]$} & {$[0.010]$} & {$[0.007]$} & [0.009] \\
\hline Observations & 2,988 & 2,988 & 2,988 & 2,988 & 2,233 & 2,233 & 2,233 & 2,233 \\
\hline \multirow[t]{2}{*}{ R-squared } & 0.098 & 0.097 & 0.404 & 0.406 & 0.217 & 0.216 & 0.193 & 0.193 \\
\hline & \multicolumn{8}{|c|}{ Panel C: Contemporaneous exposure to parental migration (dummy) } \\
\hline \multirow[t]{2}{*}{1 if parent was away at least one month last year } & $-0.197 * * *$ & $-0.269 * * *$ & $-0.105^{* *}$ & $-0.216 * * *$ & $-0.013 * * *$ & -0.001 & $-0.013 * *$ & 0.002 \\
\hline & {$[0.070]$} & [0.082] & [0.045] & {$[0.054]$} & [0.005] & [0.007] & [0.005] & [0.007] \\
\hline Observations & 2,988 & 2,988 & 2,988 & 2,988 & 2,233 & 2,233 & 2,233 & 2,233 \\
\hline R-squared & 0.096 & 0.097 & 0.403 & 0.406 & 0.219 & 0.216 & 0.195 & 0.192 \\
\hline
\end{tabular}

Standard errors in brackets, $* * * p<0.01, * * p<0.05, * p<0.1$

Note: All regressions in this table control for the full set of children's characteristics, parental characteristics, household composition, village level controls and provincial fixed effects. 
Table 4: Selected First Stage Results

\begin{tabular}{|c|c|c|c|c|}
\hline \multirow[b]{2}{*}{ Outcome variable = Lifetime exposure to parental migration } & \multicolumn{2}{|c|}{ Health Sample } & \multicolumn{2}{|c|}{ Education Sample } \\
\hline & Fathers & Mothers & Fathers & Mothers \\
\hline \multirow[t]{2}{*}{ Distance between village and prov capital city $(\mathrm{km})$} & $0.262^{* * *}$ & $0.151^{* * *}$ & $0.195^{* * *}$ & $0.114^{* * *}$ \\
\hline & [0.044] & [0.033] & [0.044] & {$[0.030]$} \\
\hline \multirow[t]{2}{*}{ Weather shocks when parent was $16-25$} & $0.006^{* *}$ & $0.005^{* * *}$ & $0.008 * * *$ & $0.007^{* * *}$ \\
\hline & [0.003] & [0.002] & [0.003] & {$[0.002]$} \\
\hline \multirow[t]{2}{*}{ Child's birth weight } & $0.003 * * *$ & $0.002 * * *$ & $0.003 * *$ & $0.002 * *$ \\
\hline & [0.001] & {$[0.001]$} & {$[0.001]$} & {$[0.001]$} \\
\hline \multirow[t]{2}{*}{ Father's height } & -0.001 & -0.001 & -0.001 & -0.001 \\
\hline & {$[0.001]$} & [0.001] & {$[0.001]$} & {$[0.001]$} \\
\hline \multirow[t]{2}{*}{ Mother's height } & 0.000 & 0.000 & 0.001 & 0.000 \\
\hline & {$[0.001]$} & {$[0.001]$} & {$[0.001]$} & {$[0.001]$} \\
\hline \multirow[t]{2}{*}{ Father's years of schooling } & 0.005 & $0.004 *$ & 0.004 & 0.003 \\
\hline & [0.003] & {$[0.002]$} & [0.003] & {$[0.002]$} \\
\hline \multirow[t]{2}{*}{ Mother's years of schooling } & 0.000 & 0.000 & 0.000 & -0.001 \\
\hline & [0.003] & [0.002] & [0.003] & {$[0.002]$} \\
\hline \multirow[t]{2}{*}{ Father's age } & $-0.006 * * *$ & -0.002 & $-0.004 * * *$ & -0.001 \\
\hline & {$[0.002]$} & [0.002] & [0.001] & {$[0.001]$} \\
\hline \multirow[t]{2}{*}{ Mother's age } & 0.000 & -0.002 & -0.001 & $-0.003 * *$ \\
\hline & {$[0.002]$} & [0.001] & {$[0.002]$} & {$[0.001]$} \\
\hline \multirow[t]{2}{*}{ Number of household members } & $0.029 * * *$ & $0.028 * * *$ & $0.028 * * *$ & $0.029 * * *$ \\
\hline & {$[0.005]$} & [0.005] & {$[0.006]$} & [0.005] \\
\hline \multirow[t]{2}{*}{ Share of adults female member (aged $>=16$ ) } & $0.118^{* *}$ & $0.173 * * *$ & 0.029 & $0.086 * *$ \\
\hline & [0.049] & [0.043] & {$[0.046]$} & {$[0.040]$} \\
\hline \multirow[t]{2}{*}{ Share of adults male member (aged $>=16$ ) } & $0.342 * * *$ & $0.370 * * *$ & $0.293 * * *$ & $0.299 * * *$ \\
\hline & [0.065] & [0.049] & {$[0.067]$} & {$[0.048]$} \\
\hline \multirow[t]{2}{*}{ Shear of children aged 12 to 15} & $0.096 * *$ & $0.057^{*}$ & $0.110 * *$ & 0.047 \\
\hline & [0.045] & [0.032] & [0.048] & {$[0.030]$} \\
\hline Gender specific age dummies for children & Yes & Yes & Yes & Yes \\
\hline Village level controls & Yes & Yes & Yes & Yes \\
\hline Provincial fixed effects & Yes & Yes & Yes & Yes \\
\hline Observations & 2,988 & 2,988 & 2,233 & 2,233 \\
\hline R-squared & 0.314 & 0.266 & 0.206 & 0.219 \\
\hline F-test for weak instruments & 22.42 & 16.63 & 16.69 & 14.12 \\
\hline \multicolumn{5}{|c|}{ Outcome variable = Contemporaneous exposure to panrental migration as the share of previous year } \\
\hline \multirow[t]{2}{*}{ Distance between village and prov capital city $(\mathrm{km})$} & $0.487 * * *$ & $0.338 * * *$ & $0.413 * * *$ & $0.295 * * *$ \\
\hline & [0.060] & [0.055] & [0.064] & [0.054] \\
\hline Weather shocks when parent was $16-25$ & $0.012 * * *$ & $0.011 * * *$ & $0.018 * * *$ & $0.015^{* * *}$ \\
\hline (separately defined for mothers and fathers) & [0.004] & [0.004] & [0.005] & {$[0.005]$} \\
\hline Observations & 2,988 & 2,988 & 2,233 & 2,233 \\
\hline R-squared & 0.256 & 0.260 & 0.245 & 0.268 \\
\hline F-test for weak instruments & 41.32 & 23.66 & 30.62 & 18.95 \\
\hline
\end{tabular}

Note: All regressions in this table control for the full set of children's characteristics, parental characteristics, household composition, village level controls and provincial fixed effects. 
Table 5: IV Results for the Effects of Parental Migration on Children's Health and Education Outcomes

\begin{tabular}{|c|c|c|c|c|c|c|c|c|}
\hline \multirow[b]{2}{*}{ Panel A: Whole Sample } & \multicolumn{2}{|c|}{ Height } & \multicolumn{2}{|c|}{ Weight } & \multicolumn{2}{|c|}{ Chinese } & \multicolumn{2}{|c|}{ Math } \\
\hline & Father & Mother & Father & Mother & Father & Mother & Father & Mother \\
\hline \multirow[t]{2}{*}{ Lifetime exposure to parental migration } & -1.576 & $-3.390 * *$ & $-1.331^{* *}$ & $-2.211^{* *}$ & $-0.283 * * *$ & $-0.361^{* *}$ & $-0.182^{*}$ & -0.173 \\
\hline & {$[1.021]$} & [1.633] & {$[0.601]$} & {$[0.954]$} & {$[0.101]$} & [0.143] & [0.098] & [0.123] \\
\hline Observations & 2,988 & 2,988 & 2,988 & 2,988 & 2,233 & 2,233 & 2,233 & 2,233 \\
\hline weak IV test & 23.72 & 13.2 & 23.72 & 13.2 & 15.65 & 12.06 & 15.65 & 12.06 \\
\hline \multirow[t]{2}{*}{$\mathrm{N}$ clusters } & 1835 & 1839 & 1835 & 1839 & 1463 & 1447 & 1463 & 1447 \\
\hline & \multicolumn{2}{|c|}{ Height } & \multicolumn{2}{|c|}{ Weight } & \multicolumn{2}{|c|}{ Chinese } & \multicolumn{2}{|c|}{ Math } \\
\hline Panel B: Sons & Father & Mother & Father & Mother & Father & Mother & Father & Mother \\
\hline \multirow[t]{2}{*}{ Lifetime exposure to parental migration } & $-1.880 *$ & $-2.915 * *$ & $-1.038^{*}$ & $-1.495^{*}$ & $-0.336 * *$ & $-0.415^{* *}$ & $-0.199 *$ & -0.192 \\
\hline & {$[1.073]$} & [1.435] & {$[0.627]$} & {$[0.847]$} & {$[0.130]$} & {$[0.165]$} & {$[0.121]$} & {$[0.150]$} \\
\hline Observations & 1,639 & 1,639 & 1,639 & 1,639 & 1,203 & 1,203 & 1,203 & 1,203 \\
\hline weak IV test & 21.45 & 18.99 & 21.45 & 18.99 & 10.39 & 12.09 & 10.39 & 12.09 \\
\hline \multirow[t]{2}{*}{ N clusters } & 1262 & 1267 & 1262 & 1267 & 946 & 946 & 946 & 946 \\
\hline & \multicolumn{2}{|c|}{ Height } & \multicolumn{2}{|c|}{ Weight } & \multicolumn{2}{|c|}{ Chinese } & \multicolumn{2}{|c|}{ Math } \\
\hline Panel C: Daughters & Father & Mother & Father & Mother & Father & Mother & Father & Mother \\
\hline \multirow[t]{2}{*}{ Lifetime exposure to parental migration } & -0.766 & -4.176 & $-1.960 *$ & -3.624 & -0.184 & -0.217 & -0.144 & -0.136 \\
\hline & [1.845] & {$[3.881]$} & [1.138] & {$[2.425]$} & {$[0.126]$} & {$[0.185]$} & [0.135] & {$[0.160]$} \\
\hline Observations & 1,349 & 1,349 & 1,349 & 1,349 & 1,030 & 1,030 & 1,030 & 1,030 \\
\hline weak IV test & 7.739 & 2.281 & 7.739 & 2.281 & 7.635 & 5.119 & 7.635 & 5.119 \\
\hline \multirow[t]{2}{*}{$\mathrm{N}$ clusters } & 1065 & 1067 & 1065 & 1067 & 841 & 834 & 841 & 834 \\
\hline & \multicolumn{2}{|c|}{ Height Z score } & \multicolumn{2}{|c|}{ Weight Z score } & \multicolumn{2}{|c|}{ Chinese test score } & \multicolumn{2}{|c|}{ Math test score } \\
\hline Panel E: Contemporaneous Effect (share) & Father & Mother & Father & Mother & Father & Mother & Father & Mother \\
\hline \multirow[t]{2}{*}{ No. of months last year parents away/12 } & -0.815 & $-1.533^{* *}$ & $-0.693 * *$ & $-1.013^{* *}$ & $-0.131 * * *$ & $-0.156 * * *$ & $-0.085^{* *}$ & -0.076 \\
\hline & [0.529] & {$[0.721]$} & {$[0.310]$} & {$[0.418]$} & {$[0.042]$} & {$[0.057]$} & [0.043] & {$[0.051]$} \\
\hline Observations & 2,988 & 2,988 & 2,988 & 2,988 & 2,233 & 2,233 & 2,233 & 2,233 \\
\hline weak IV test & 43.54 & 26.76 & 43.54 & 26.76 & 30.92 & 21.32 & 30.92 & 21.32 \\
\hline \multirow[t]{2}{*}{$\mathrm{N}$ clusters } & 1835 & 1839 & 1835 & 1839 & 1463 & 1447 & 1463 & 1447 \\
\hline & \multicolumn{2}{|c|}{ Height Z score } & \multicolumn{2}{|c|}{ Weight Z score } & Chinese $t$ & test score & Math & est score \\
\hline Panel F: Contemporaneous Effect (dummy) & Father & Mother & Father & Mother & Father & Mother & Father & Mother \\
\hline 1 if parent was away at least one month last year & -0.678 & $-1.075^{* *}$ & $-0.572 * *$ & $-0.731^{* *}$ & $-0.099 * * *$ & $-0.121 * * *$ & $-0.062^{*}$ & -0.059 \\
\hline & {$[0.434]$} & {$[0.511]$} & {$[0.256]$} & [0.299] & {$[0.032]$} & [0.043] & [0.033] & {$[0.040]$} \\
\hline Observations & 2,988 & 2,988 & 2,988 & 2,988 & 2,233 & 2,233 & 2,233 & 2,233 \\
\hline weak IV test & 33.91 & 28.98 & 33.91 & 28.98 & 27.21 & 20.41 & 27.21 & 20.41 \\
\hline N clusters & 1835 & 1839 & 1835 & 1839 & 1463 & 1447 & 1463 & 1447 \\
\hline
\end{tabular}

Standard errors in brackets, ${ }^{* * *} p<0.01, * * p<0.05, * p<0.1$

Note: All regressions in this table control for the full set of children's characteristics, parental characteristics, household composition, village level controls and provincial fixed effects. 
Table 6: Sensitivity Tests

\begin{tabular}{|c|c|c|c|c|c|c|c|c|}
\hline & \multicolumn{8}{|c|}{ Panel A: Use the Alternative Migration Measure Based on the Start of the First Migration Spell } \\
\hline & \multicolumn{2}{|c|}{ Height } & \multicolumn{2}{|c|}{ Weight } & \multicolumn{2}{|c|}{ Chinese } & \multicolumn{2}{|c|}{ Math } \\
\hline & Father & Mother & Father & Mother & Father & Mother & Father & Mother \\
\hline \multirow[t]{2}{*}{ Lifetime exposure to parental migration } & -0.995 & $-1.675^{* *}$ & $-0.833^{* *}$ & $-1.052 * *$ & $-0.156^{* * *}$ & $-0.167 * * *$ & $-0.095^{*}$ & -0.080 \\
\hline & [0.633] & [0.798] & {$[0.370]$} & {$[0.462]$} & {$[0.055]$} & [0.063] & [0.054] & [0.055] \\
\hline Observations & 2,988 & 2,988 & 2,988 & 2,988 & 2,233 & 2,233 & 2,233 & 2,233 \\
\hline weak IV test & 23.05 & 19.58 & 23.05 & 19.58 & 14.6 & 13.82 & 14.6 & 13.82 \\
\hline \multirow[t]{3}{*}{ N clusters } & 1835 & 1839 & 1835 & 1839 & 1463 & 1447 & 1463 & 1447 \\
\hline & \multicolumn{8}{|c|}{ Panel B: Redefine Drought IV to When Parents Aged 16-21 } \\
\hline & Father & Mother & Father & Mother & Father & Mother & Father & Mother \\
\hline \multirow[t]{2}{*}{ Lifetime exposure to parental migration } & -1.310 & -2.245 & $-1.041^{*}$ & $-1.697^{*}$ & $-0.264^{* *}$ & $-0.329 * *$ & -0.168 & $-0.273^{* *}$ \\
\hline & [1.014] & {$[1.541]$} & [0.603] & [0.915] & [0.115] & [0.141] & [0.109] & {$[0.134]$} \\
\hline Observations & 2,988 & 2,988 & 2,988 & 2,988 & 2,233 & 2,233 & 2,233 & 2,233 \\
\hline weak IV test & 22.14 & 12.61 & 22.14 & 12.61 & 12.84 & 11.6 & 12.84 & 11.6 \\
\hline \multirow[t]{4}{*}{$\mathrm{N}$ clusters } & 1835 & 1839 & 1835 & 1839 & 1463 & 1447 & 1463 & 1447 \\
\hline & \multicolumn{8}{|c|}{ Panel C: Use Consistently Measured Math Test Score as Dependent Variable } \\
\hline & \multicolumn{4}{|c|}{ Lifetime exposure } & \multicolumn{4}{|c|}{ Contemporarenous exposure } \\
\hline & & Father & Mother & & & Father & Mother & \\
\hline Lifetime or contemporaneous exposure to & & $-0.618^{* *}$ & $-0.716^{* *}$ & & & $-0.029 * *$ & $-0.045^{* *}$ & \\
\hline parental migration as a share & & {$[0.258]$} & {$[0.325]$} & & & [0.012] & {$[0.022]$} & \\
\hline Observations & & 506 & 506 & & & 516 & 516 & \\
\hline weak IV test & & 5.911 & 6.615 & & & 8.366 & 4.844 & \\
\hline $\mathrm{N}$ clusters & & 397 & 405 & & & 402 & 412 & \\
\hline
\end{tabular}

Standard errors in brackets, $* * * p<0.01, * * p<0.05, * p<0.1$

Note: All regressions in this table control for the full set of children's characteristics, parental characteristics, household composition, village level controls and provincial fixed effects. 
Table 7: Selected Results from Estimation of Inputs into Education Equations

\begin{tabular}{|c|c|c|c|c|c|c|c|c|}
\hline $\begin{array}{l}\text { This version is based on the cleaning of four } \\
\text { outcome variables }\end{array}$ & $\begin{array}{l}\text { Age at which } \\
\text { child started } \\
\text { school }\end{array}$ & $\begin{array}{l}\text { Gap between } \\
\text { age and grade }\end{array}$ & $\begin{array}{l}1 \text { if child is } \\
\text { enrolled }\end{array}$ & $\begin{array}{l}\text { Distance to } \\
\text { school }\end{array}$ & 1 if boarding & $\begin{array}{l}\text { Hours studied } \\
\text { off school per } \\
\text { week }\end{array}$ & $\begin{array}{l}\text { Annual fee paid } \\
\text { (1,000 Yuan) }\end{array}$ & $\begin{array}{c}\text { Private tutorial } \\
\text { expenditure } \\
(1,000 \text { Yuan) }\end{array}$ \\
\hline $\begin{array}{l}\text { Mean of the outcome variable } \\
\text { SD of the outcome variable }\end{array}$ & $\begin{array}{c}6.665 \\
{[0.710]} \\
\end{array}$ & $\begin{array}{c}6.079 \\
{[1.229]} \\
\end{array}$ & $\begin{array}{c}0.992 \\
{[0.087]} \\
\end{array}$ & $\begin{array}{c}3.913 \\
{[11.404]} \\
\end{array}$ & $\begin{array}{c}0.329 \\
{[0.470]} \\
\end{array}$ & $\begin{array}{c}7.139 \\
{[6.155]} \\
\end{array}$ & $\begin{array}{c}0.755 \\
{[1.309]} \\
\end{array}$ & $\begin{array}{c}0.053 \\
{[0.377]} \\
\end{array}$ \\
\hline Lifetime exposure to paternal migration & $\begin{array}{l}-0.552 \\
{[0.585]}\end{array}$ & $\begin{array}{c}2.832 * * * \\
{[0.980]}\end{array}$ & $\begin{array}{l}-0.014 \\
{[0.061]}\end{array}$ & $\begin{array}{l}-4.016 \\
{[6.982]}\end{array}$ & $\begin{array}{l}0.858 * * \\
{[0.424]}\end{array}$ & $\begin{array}{c}-20.470 * * * \\
{[6.096]}\end{array}$ & $\begin{array}{l}-0.091 \\
{[0.928]}\end{array}$ & $\begin{array}{c}-0.480 * * \\
{[0.189]}\end{array}$ \\
\hline $\begin{array}{l}\text { Observations } \\
\text { weak IV test } \\
\mathrm{N} \text { clusters }\end{array}$ & $\begin{array}{l}2,232 \\
15.55 \\
1462 \\
\end{array}$ & $\begin{array}{l}2,191 \\
15.68 \\
1440 \\
\end{array}$ & $\begin{array}{l}2,231 \\
15.62 \\
1463 \\
\end{array}$ & $\begin{array}{l}2,202 \\
15.24 \\
1448 \\
\end{array}$ & $\begin{array}{l}2,210 \\
15.62 \\
1453 \\
\end{array}$ & $\begin{array}{l}2,233 \\
15.65 \\
1463 \\
\end{array}$ & $\begin{array}{c}2,171 \\
14.65 \\
1439 \\
\end{array}$ & $\begin{array}{c}2,083 \\
14.09 \\
1396 \\
\end{array}$ \\
\hline Lifetime exposure to maternal migration & $\begin{array}{c}-0.781 \\
{[0.887]}\end{array}$ & $\begin{array}{c}4.048^{* * *} \\
{[1.408]}\end{array}$ & $\begin{array}{c}0.019 \\
{[0.075]}\end{array}$ & $\begin{array}{c}-3.717 \\
{[9.579]}\end{array}$ & $\begin{array}{c}0.711 \\
{[0.531]}\end{array}$ & $\begin{array}{c}-25.612^{* * *} \\
{[8.227]}\end{array}$ & $\begin{array}{c}-0.051 \\
{[1.336]}\end{array}$ & $\begin{array}{c}-0.547^{* *} \\
{[0.248]}\end{array}$ \\
\hline $\begin{array}{l}\text { Observations } \\
\text { weak IV test } \\
\mathrm{N} \text { clusters }\end{array}$ & $\begin{array}{l}2,232 \\
11.97 \\
1447\end{array}$ & $\begin{array}{c}2,191 \\
11.75 \\
1424\end{array}$ & $\begin{array}{c}2,231 \\
12.03 \\
1446\end{array}$ & $\begin{array}{c}2,202 \\
11.9 \\
1430\end{array}$ & $\begin{array}{l}2,210 \\
12.08 \\
1435\end{array}$ & $\begin{array}{l}2,233 \\
12.06 \\
1447\end{array}$ & $\begin{array}{c}2,171 \\
11.5 \\
1423\end{array}$ & $\begin{array}{l}2,083 \\
10.92 \\
1375\end{array}$ \\
\hline
\end{tabular}

Standard errors in brackets, ${ }^{* * *} p<0.01,{ }^{* *} p<0.05,{ }^{*} p<0.1$ 
Figure 1: Distribution of the Outcome Variables
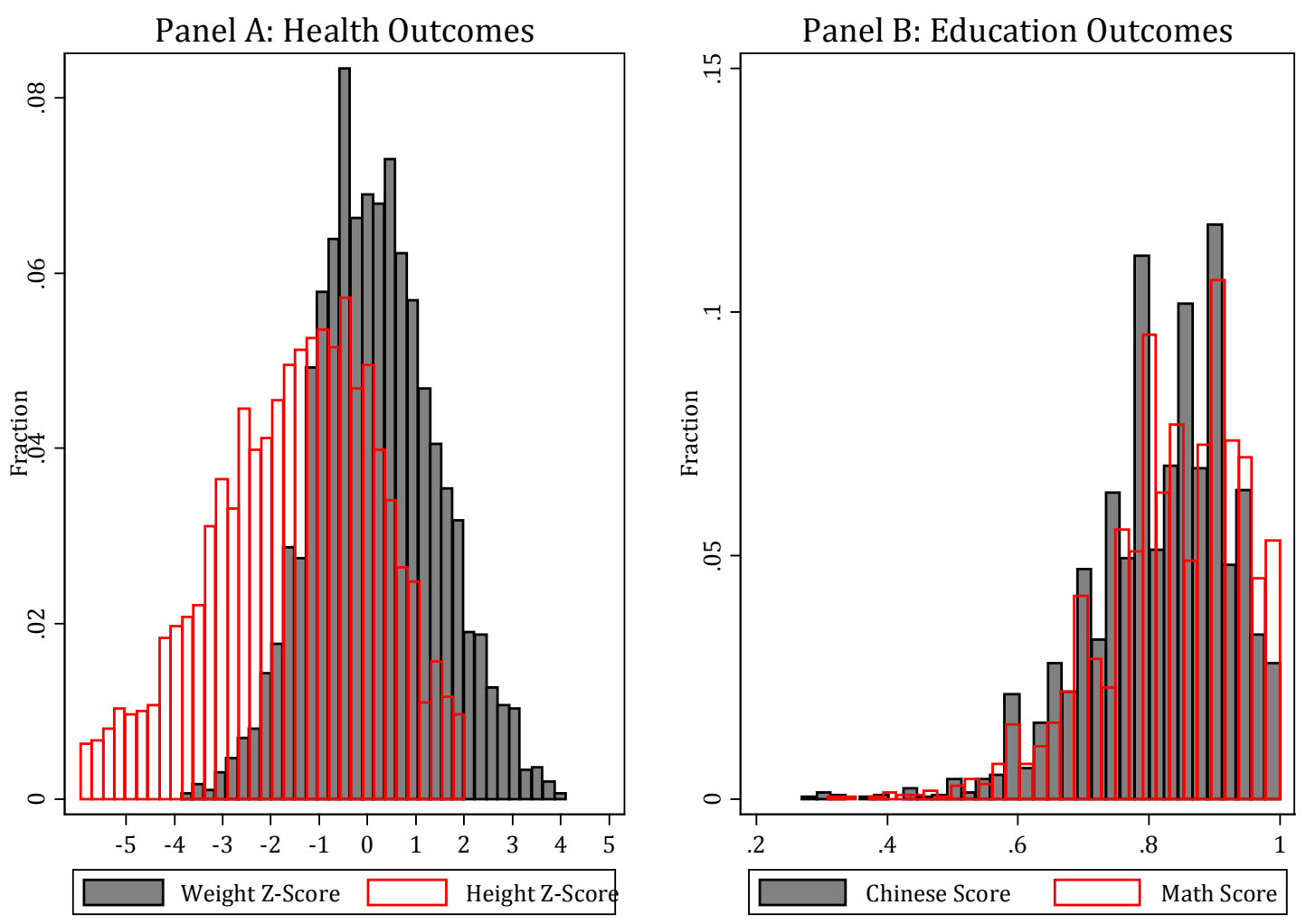
Figure 2: Parental Migration as Proportion of Children’s Lifetime
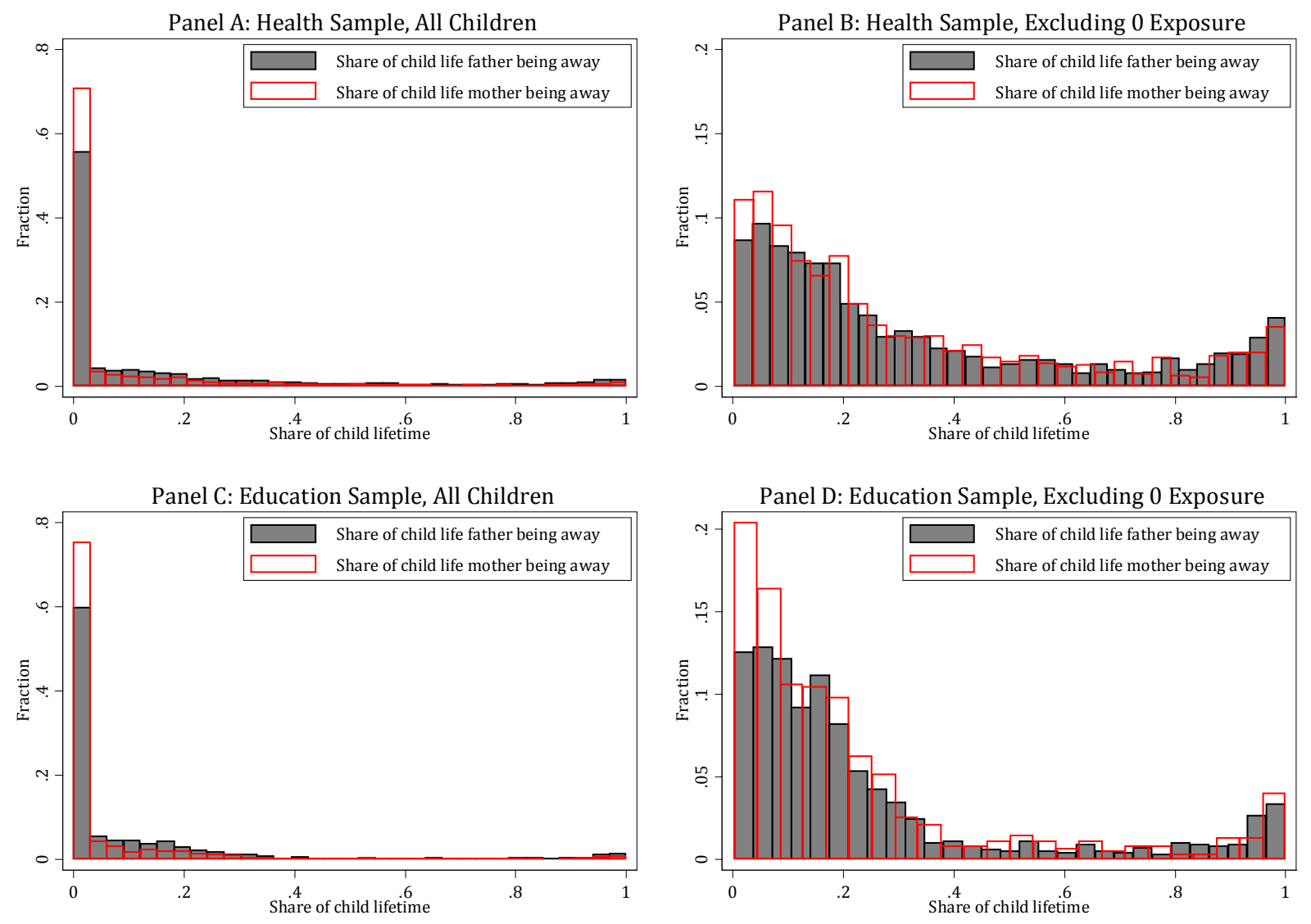
Figure 3: Unconditional local linear regression of the relationship between outcomes and parental migration
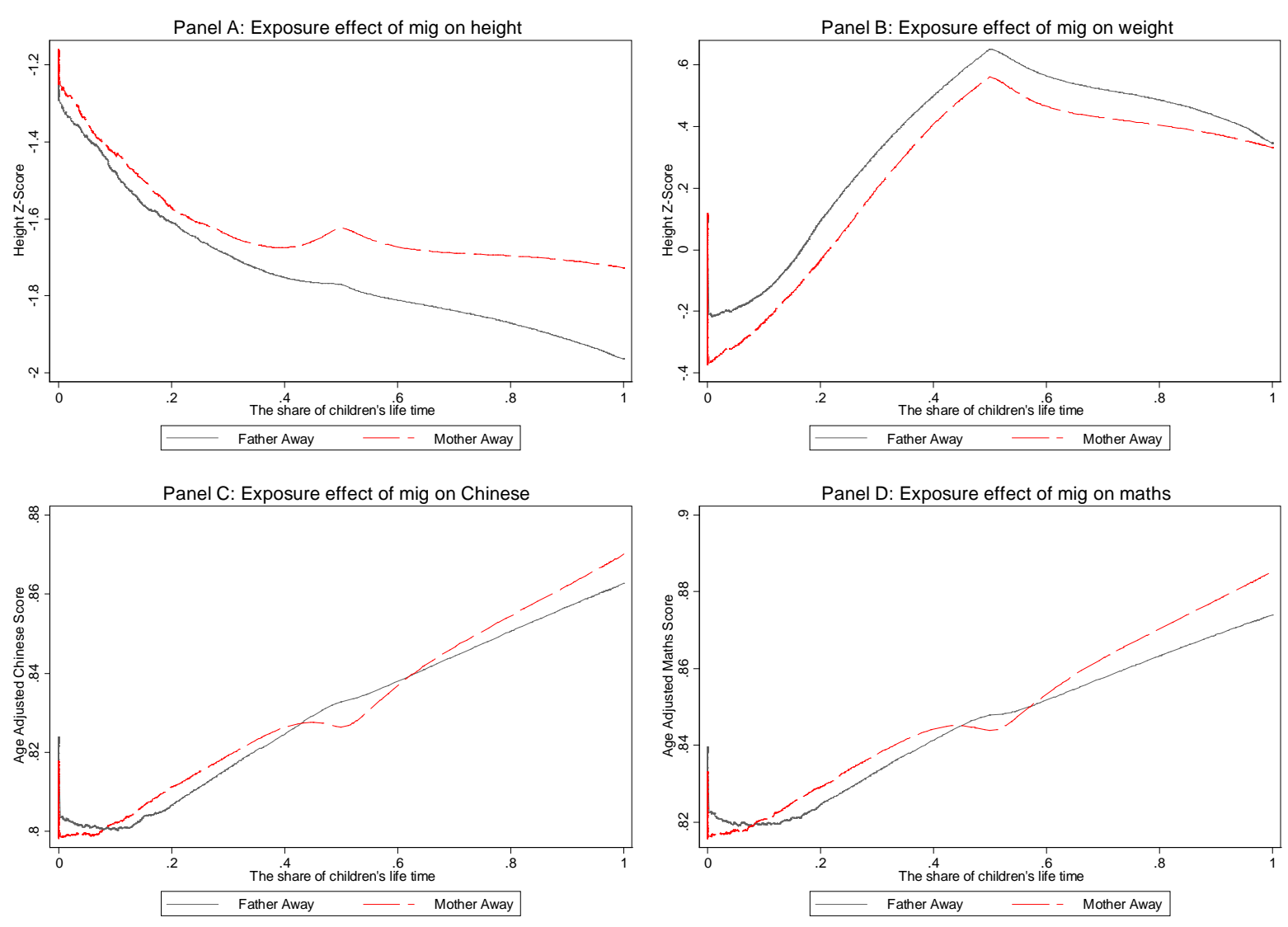


\section{Appendix A: Data Appendix}

The share of child life in which parents were away: The RUMiC Study provides two types of information. One is the number of months in the previous year during which parents were away from home. This information is available from all the waves. Thus, we know the number of months parents were away in 2007, 2008, and 2009. The other piece of information is when parents started migration. This was asked only in the 2009 wave for individuals who reported to have been away in 2008. In order to construct the number of months parents were away since the beginning of migration asked in the 2009 survey till the end of 2009, we first aggregated the number of months in which parents were away in 2007 through 2009. For individuals who answered that their migration had started before 2007, we have added the number of months between the beginning of the migration till the end of 2006.

Individual test scores were asked for the previous semester, together with the full score for each subject. The ratio of the individual score over the full score is used as our outcome variables.

Distance to public facilities is coded using five categories: $1:<2 \mathrm{~km}, 2: 2-5 \mathrm{~km}, 3: 5-10$ $\mathrm{km}, 4: 10-20 \mathrm{~km}, 5:>20 \mathrm{~km}$.

The height-for-age Z-score is created using parameters from the CDC 2000 Growth Charts and 2006 WHO Growth Charts (Kuczmarski RJ, Ogden CL, Guo SS, et al. 2000; WHO, 2006; de Onis, et al., 2007). The results do not change substantively depending on the choice over the two parameter sources. In this paper, we report the estimates based on the CDC parameters because they provide a more suitable reference group for our analysis. In the WHO growth charts, the comparison group for children aged 0-5 are children following optimal health practices. Thus, the charts depict the standard which is likely to realize under optimal conditions, rather than just a reference. However, the same standard was not used for the comparison group for 5-19 year-olds, and it is based on the U.S. reference children used in the 1977 NCHS Growth Charts. On the other hand, the CDC 2000 charts provide a more consistent reference for children in our sample, based on a group of children in the U.S.

We apply the CDC parameters for infants (based on length) to observations aged 024 months, and the parameters for children (based on statue) observations aged 25-180 months. The transition between these two charts have been made smooth in the 2000 CDC charts (Kuczmarski RJ, Ogden CL, Guo SS, et al. 2000).

Since our anthropometric data are based on reports by parents, there are likely to be measurement errors. Several methods have been suggested to deal with them. The WHO recommends the use of different formula for those children whose z-scores are larger than 3 
in the absolute terms. The CDC training modules contain a note suggesting to distinguish "biologically implausible values," 19 which are observations whose z-scores are larger than certain values, or are away from the mean z-score in terms of standard deviations. We report the results that are commonly found regardless of the choice over these alternative adjustments to the measures for outcomes.

\footnotetext{
${ }^{19}$ http://www.cdc.gov/nccdphp/dnpa/growthcharts/resources/BIV-cutoffs.pdf, downloaded on Jan-
} uary 28 th, 2013. 